\title{
Credibility and Commitment in Crisis Bargaining*
}

\author{
Mark Fey \\ University of Rochester \\ Adam Meirowitz \\ Princeton University \\ Kristopher W. Ramsay \\ Princeton University
}

February 28, 2013

\begin{abstract}
Although scholars of international security share a skepticism for the extent to which agreements can be externally enforced, much existing game-theoretic work involves strong forms of commitment. Building on the canonical model of crisis bargaining we study the role of two forms of commitment in bargaining - the ability to commit to a settlement and the ability to commit to end negotiations and initiate war fighting. We show that, contrary to expectations, allowing a proposer to retract their offer after learning of its acceptance does not lead to greater demands. Instead, a rational actor can be best off honoring the accepted agreement in crisis bargaining, even though the act of accepting an offer changes the proposer's beliefs about the probability that an offer is acceptable. On the other hand, allowing a proposer to continue bargaining in lieu of fighting does change the dynamics of bargaining, although this effect diminishes as players become more patient. Finally, when there is not commitment to offers or fighting after a rejected proposal, the behavior is the same as that found in the model with only renegotiation of agreements and thus mirrors the behavior in the model in which both forms of commitment are present.
\end{abstract}

*We thank Avi Acharya, Alex Hirsch, Matias Iaryczower, David Myatt, and Francesco Squintani for useful discussions on this topic. We appreciation helpful comments at the University Wisconsin, Yale, SUNYBinghamton, University of Warwick, the London School of Economics, and the University of Rochester. 


\section{Introduction}

If you give in, you will immediately be confronted with some greater demand, since they will think that you only gave way on this point out of fear.

-Pericles, in Thucydides, 1972 (p.402)

Modern theories of war describe international crises as bargaining problems and then explain war as the result of bargaining failure. In this view crises are bargaining situations where a dispute over a divisible good or policy can result in some form of peaceful settlement or war. These theoretical models of crisis bargaining rely heavily on economic bargaining models first created to study different phenomenon. Therefore, two important questions merit answers: does bargaining between countries differ in important ways from economic bargaining and do these differences imply important changes in the predictions of international bargaining outcomes?

In almost all models of bargaining, whether they are applied to bilateral trade, labor strikes, or war, uncertainty is a key feature of the environment. When there is incomplete information, players can potentially learn from the bargaining process, given the proposals that are made and the responses of actors to those proposals. To a great extent the analysis of the learning process in bargaining has been shaped by studying bargaining in economic settings. For example, haggling in markets, buying a house, or sales in a retail store all have a similar structure. In these environments, to the extent that there is learning, proposals are made or prices are set and sometimes rejected. Rejected offers lead to decreases in prices over time, though there is some cost to delay, and once an agreement is reached the bargaining-and the models of bargaining-ends (Ausubel et al. 2002). In these contexts, it seems sensible that agreement is final because there is either a transfer of property (in the market setting) or an enforceable contract (in a housing sale).

However, in the context of international relations, there is no external enforcement of agreements and there is rarely an immediate transfer of property. This suggests that the assumption that agreement is final may be less appropriate in this crisis bargaining setting. Nonetheless, many have used similar models of bargaining to analyze the influence of asymmetric information on the probability of war (Brito and Intriligator 1985, Fearon 1995, Fey and Ramsay 2011). The standard economics model also has been extended by many scholars to include new and important features when studying crisis bargaining. For example, Filson 
and Werner (2002), Slantchev (2003), Smith and Stam (2004), Powell (2004) all add the inside option of fighting costly battles during the bargaining process to allow learning from both equilibrium actions and possibly battlefield outcomes. Common to all these models, the learning happens during the disagreement phase of the bargaining. Because the game ends when an agreement is reached, and the settlement is at a minimum implemented for a single period, this commitment to agreement has ruled out immediate strategic responses to acceptance.

The modern theory of war, largely in a separate literature, has also considered another common cause of bargaining failure: the commitment problem. These arguments focus on the lack of enforcement for peaceful agreements and how concerns about changes in future preferences or relative military capabilities influence the prospects for peace (Fearon 1995, Powell 2006, Leventoğlu and Slantchev 2007, Tingley 2011). Once the commitment problem is acknowledged, many questions arise regarding existing models. Using formal theory to understand commitment simultaneously clarifies and obscures these issues. While ideas like sequential rationality require "in game" commitments to be credible the choice of extensive form, by definition, presupposes players are committed to that particular set of actions and timing. That is, any game form used to study commitment starts with the assumption that players are committed to the game under analysis. In the ultimatum bargaining game, for example, there is a commitment to accepted offers being enforced and to rejection of offers causing war.

In the standard bargaining model of war there are two kinds of commitments we will relax. First we are interested in bargaining when there is no commitment to enacting accepted agreements. Second we consider crisis bargaining with no commitment to fighting. Finally we are interested in the case where there is no commitment to agreements or fighting. Unlike Fearon (1995),Leventoğlu and Slantchev (2007), and Powell (2006), we focus on how the commitment problem operates in the presence of incomplete information. Wolford et al. (2011) consider a similar situation, but our analysis differs from theirs. In the Wolford et al. model the commitment problem arises from a change in "long run" fundamentals, i.e. a between period shift in the known distribution of power. We focus instead on how changes in beliefs, and hence short run non-fundamental aspects of the crisis environment, might influence bargaining and the probability of war.

We are concerned with how these short run changes affect behavior. One might think, like Schelling (1960, p.93), that "[o]ne never quite knows in the course of a diplomatic confrontation how opinion will converge on signs of weakness. One never quite knows what 
exits will begin to look cowardly to oneself or to the bystanders or to one's adversary. It would be possible to get into a situation in which either side felt that to yield now would create such an asymmetric situation, would be such a gratuitous act of surrender, that whoever backed down could not persuade anybody that he wouldn't yield again tomorrow and the day after." Continuing with the example of ultimatum bargaining, we ask: if accepting an offers signals weakness of power or high cost of war, does that open an opportunity for the proposer to make further demands? If an offer is rejected, might the proposer want to make a last-ditch effort to avoid a conflict? Does the first dynamic increase the risk of war? Does the second lower the risk of war?

We find, contrary to the concern of Schelling, learning that the opponent is willing to accept the proposed offer does not create an incentive for the proposer to retract the accepted proposal and try to renegotiate the deal. Indeed, in an ultimatum model in which the proposer is allowed to renegotiate an accepted offer, the equilibrium path of play is exactly that of the one-shot ultimatum game. Essentially, the optimal offer in the one-shot version incorporates the risk-reward tradeoff and learning that an offer is accepted does not change how this tradeoff is evaluated. Next, in a model in which agreement is final but rejection can be renegotiated, although there can be delay in agreement, this is due to the ability of the proposer to weaken the responder's bargaining position by delaying their outside option. As the cost of delay goes to zero, equilibrium behavior converges to that of the one-shot ultimatum game. Finally, we study a model with both of these features, renegotiation of both agreement and rejection, as well as an option for the responder to immediately fight, and we find once again that equilibrium behavior mirrors that of the one-shot ultimatum game.

Another way to state our findings is that, in terms of equilibrium behavior, the ultimatum model with retractable offers is observationally equivalent to a one-shot ultimatum game. This fact has both empirical and theoretical implications. First, it suggests that it may be very difficult to assess empirically whether offers are indeed retractable in real-world negotiations; we would not expect to see any offers being retracted in either case. Second, it shows that in some sense the findings of the one-shot ultimatum model are robust to the relaxation of commitment assumptions. Even though agreements may not be binding in crisis bargaining, due to lack of external enforcement, etc., in equilibrium parties to the negotiation act as if they are. This is reassuring given the centrality of the ultimatum game in the theoretical study of conflict.

An analogue to our concern about commitment to not renegotiate after an offer is ac- 
cepted surfaces in the contracting literature, but with very different results. Hart and Tirole (1988) consider the distinction between rental and sales contracts. In a rental market the seller can renegotiate the price for rental in subsequent periods, which is analogous to being able to raise the price after learning that the buyer was willing to pay a particular rental fee, modulo a one period flow payoff. In contrast the sales market does not allow such renegotiation because the property right changes once a deal is struck. In analyzing both types of markets, Hart and Tirole assume that following rejection the seller can offer a lower price. Thus their model of the rental market involves relaxing commitment to delivery and to bargaining failure. Put loosely they have relaxed both the commitment to "taking it" and "leaving it." ${ }^{1}$ Here a ratchet effect is present. If the buyer accepts a price she reveals information about her valuation and this information can be used against her when the seller announces future rental prices. As a result of the buyer understanding this incentive, very little price discrimination occurs in equilibrium. ${ }^{2}$

Fearon (2007) has recently built on the Hart and Tirole framework to allow for information transmission through the fighting of battles. His model is similar to that of Hart and Tirole, but in every period in which a deal is not reached there is the possibility of an informative battle. As a model of learning by fighting this contribution is interesting and distinct. The starting point, however, of Fearon's paper is the argument that the ratchet effect that surfaces in the rental models will also be present in the security context. On this point, further elaboration is needed. We find that an important distinction between the trade and security contexts leads to very different results about the importance of commitment. The bilateral trade models typically assume that the second mover has private information about her valuation of the item up for sale or rent. In the security context the private information is thought to be about the payoff to fighting. Thus, in the trade models there is private information about the agreement outcome and in the security context there is private information about the disagreement or outside option. In the trade context, when the seller can offer a second price following rejection of her first offer it is possible for her to screen the buyer. The cost of discounting and the fact that a buyer's agreement payoff depends on her type can be sufficient to satisfy a single-crossing condition. In the security context, however, screening can not be supported by type specific variation in the continuation payoffs to accepting offers because the second player's agreement payoff does

\footnotetext{
${ }^{1}$ See also Laffont and Tirole (1988).

${ }^{2}$ The paper goes on to show that with a richer set of contracts it is possible to sustain renegotiation proof equilibria in which the seller does get to price discriminate in the rental market, thus establishing an equivalence between seller revenue in rental and sales markets.
} 
not depend on her type. If the proposer is to offer different offers across time, then weak types will be willing to pretend to be strong types, rejecting the first offer and then accepting a better subsequent offer. Fearon's model yields results that are closer to Hart and Tirole because there is an exogenous source of information (the possibility of battles which provide information about the player's types in any period of delay). Thus this model is analyzing a different mechanism than ours. To paraphrase Groucho Marx, we are interested to know if a proposer would ever want to be party to a settlement that its opponent was willing to accept?

We develop our analysis to understand the interaction of incomplete information, learning, and commitment in the crisis bargaining model. First we walk through a two period two type model of crisis bargaining. Sequentially, we analyze this model with no commitment to agreements, then no commitment to fighting, and then when neither form of commitment is present. This analysis focuses on the case with two types making clear the incentives surrounding the decision to renegotiate accepted offers and make additional proposals that may avert costly conflict. We then examine whether the conclusions are robust to a larger type space. We consider the case where the second player's type is drawn from a continuum and find that the main results carry over. We, again, find that the opportunity to learn from and react to the fact that an offer is agreeable does not change the strategic incentives of a proposer.

\section{The Baseline Model}

The baseline model for our analysis and comparison is the standard crisis bargaining ultimatum game (Fearon 1995). In this game there is a resource of unit size under dispute by two countries. Country 1 makes a proposal of a division of the resource where it keeps a share $x \in[0,1]$, leaving $1-x$ for the other country. Country 2 can then accept or reject this offer. If accepted there is a peaceful settlement of the dispute and the payoffs are equal to the shares $x$ and $1-x$. If the proposal is rejected, war occurs. In the case of war, country 1 wins the resource with a known probability $p$ and country 2 wins with the complementary probability, $1-p$. To simplify notation, we sometimes write $p_{i}$ for the probability that country $i$ wins a conflict, where $p_{1}=p$ and $p_{2}=1-p$. Each side to the dispute pays a cost $c_{i}$ if war occurs. Thus, the expected payoff to war to country $i$ is $p_{i}-c_{i}$.

It is well know that because war is costly, there exists a set of peaceful agreements that both countries prefer to fighting. In the complete information environment the probability 
of the dispute turning to war is zero. In the unique subgame perfect equilibrium to this crisis bargaining game country 1 demands the largest share that country 2 will accept, which is $x^{*}=p+c_{2}$.

With uncertainty things are more interesting. We consider a model with one-sided incomplete information. We assume that country 1's cost, $c_{1}$ is common knowledge and country 2 's cost, $c_{2}$, is private information. To start we also assume that country 2 can have two possible cost types. Let $c_{2}=c_{H}$ with probability $q$ and $c_{2}=c_{L}$ with probability $1-q$, where $0<c_{L}<c_{H}$. We denote the high cost type of country 2 by $2 H$ and the low cost type of country 2 by $2 L$. Later we will extend our results to the case with a continuum of types.

Under these assumptions, the standard model has a unique equilibrium whose nature depends on the value of $q$. We are going to focus on settings in which the equilibrium places a positive probability of war. If $q>\left(c_{L}+c_{1}\right) /\left(c_{H}+c_{1}\right)$, then the proposer demands an equilibrium share $x^{*}=p+c_{H}$, the low cost type of country 2 rejects this proposal and the high cost type of country 2 accepts. In the two type case, this is the equilibrium with a risk-reward trade-off. The proposer is willing to risk war with the low cost type in order to get the better settlement when there is peace with the high cost type.

In what follows, we let $q^{*}=\left(c_{L}+c_{1}\right) /\left(c_{H}+c_{1}\right)$ and refer to the assumption that $q>q^{*}$ as the screening condition. This is because the equilibrium offer in this case serves to screen the low type from the high type by inducing different responses from the two types.

\section{No Commitment to Agreements}

In the baseline model with incomplete information, the screening offer generates different responses from the two types. Thus, country 1 learns the true type of country 2 , but is unable to act on this information in the baseline model. We now make the simplest modification to the standard model to allow for the possibility of retractable offers and, by this change, relax the assumed level of commitment to agreements in crisis bargaining.

In this new model, illustrated in Figure 1, country 1 still gets to make an initial offer $\left(x_{1}, 1-x_{1}\right)$, and if it is rejected the game ends with war. If, however, country 2 accepts the offer then country 1 can agree, obtaining the payoffs $\left(x_{1}, 1-x_{1}\right)$ or renegotiate. If country 1 renegotiates then it makes a second proposal $x_{2}$ at some future time. This second proposal is a true take-it-or-leave-it offer. As is standard, all payoffs in the second period are discounted by the discount factor $\delta \in(0,1]$. If the second proposal is accepted then the payoffs for country 1 and country 2 are $\delta x_{2}$ and $\delta\left(1-x_{2}\right)$. If the second proposal is rejected, then war 


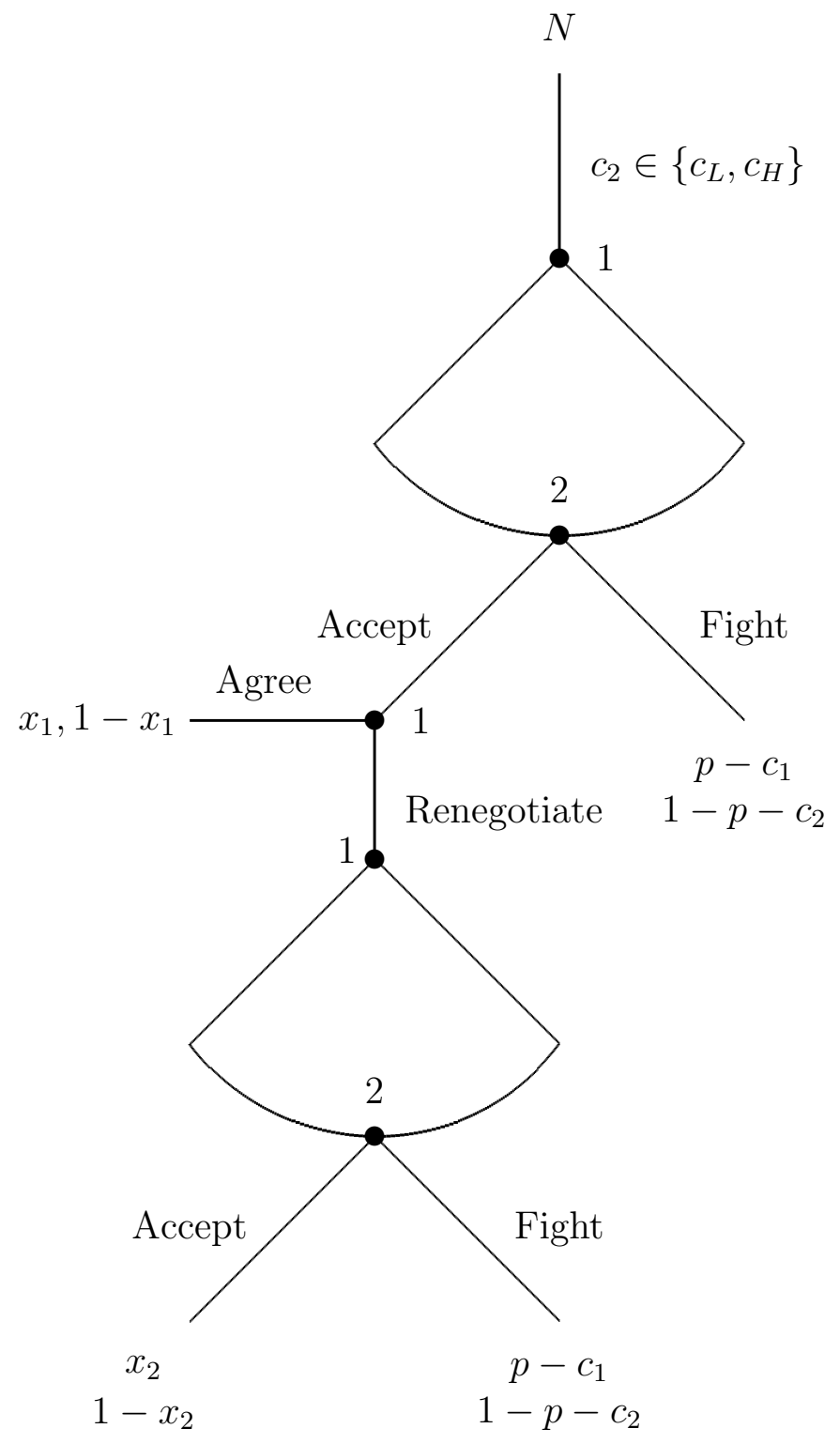

Figure 1: The game $G_{A}$, with no commitment to agreements 
ensues and its payoff is discounted by $\delta$. So rejection in the first period leads to immediate war, but acceptance can be renegotiated. We therefore label rejection of an offer as a choice by country 2 to fight. We refer to this game as $G_{A}$.

Our equilibrium concept is (strong) perfect Bayesian equilibrium, as defined by Fudenberg and Tirole (1991). The key requirement of this definition is that if country 1 deviates in the first period by making an off-the-equilibrium-path offer, it must still use the strategy of country 2 in response to this offer to calculate its belief (via Bayes' Rule) in period 2.

In the model without commitment to agreements, when $q>q^{*}$ and $\delta<1$, there is a unique (strong) perfect Bayesian equilibrium outcome.

Proposition 1. Assume $q>q^{*}$ and $\delta<1$. Then every strong PBE of game $G_{A}$ has the same equilibrium path as the one-shot ultimatum game.

Before providing the technical details in support of this result, it is useful to understand the intuition for the result and the implications for learning in crisis bargaining. This result says that even though we permit country 1 to retract its offer and renegotiate, it chooses not to do so in equilibrium. Specifically, because the low cost type rejects the initial offer of country 1 and the high cost type accepts, after observing an acceptance country 1 knows for sure that it is facing a high cost type. What may be surprising about this result is that even at this point, with all uncertainty resolved, country 1 does not renegotiate even though it has learned the type of country 2 with certainty. The reason for this is that country 1's initial equilibrium offer $x^{*}=p+c_{H}$ is the same as the optimal offer for country 1 when it knows for sure that it is facing the high cost type of country 2. Thus there is no incentive for country 1 to make a different offer in the second period, even after learning the type of the country it faces.

We now lay out some useful facts that will aid in our proof of the Proposition. We begin our analysis in the second period. Let $\mu_{A}\left(x_{1}\right)$ denote the belief of country 1 about the type of country 2 in the second period after an offer $x_{1}$ in the first period. Specifically, $\mu_{A}\left(x_{1}\right)=P\left[c_{2}=c_{H} \mid x_{1}\right.$ accepted $]$, the probability that country 1 believes country 2 is the high cost type. As period 2 is just a standard ultimatum game, we know from standard arguments that in every PBE, $x_{2} \in\left\{p+c_{L}, p+c_{H}\right\}$. Moreover, these standard arguments yield $x_{2}=p+c_{L}$ if $\mu_{A}<q^{*}, x_{2}=p+c_{H}$ if $\mu_{A}>q^{*}$, and country 1 is indifferent between making these two offers if $\mu_{A}=q^{*}$. Finally, we know from standard arguments that if $x_{2}=p+c_{L}$ in equilibrium, then both types of country 2 accept this offer with probability one, and if $x_{2}=p+c_{H}$ in equilibrium, then $2 H$ accepts with probability one and $2 L$ 
fights with probability one. Therefore, it is easy to see that whatever value $\mu_{A}$ takes, the (undiscounted) payoff to $2 L$ in period 2 is $1-p-c_{L}$. Moreover, the (undiscounted) payoff to $2 H$ is in the interval $\left[1-p-c_{H}, 1-p-c_{L}\right]$. Likewise, the (undiscounted) payoff to country 1 is $v_{1}^{*}\left(\mu_{A}\left(x_{1}\right)\right)$, where

$$
v_{1}^{*}(\mu)=\max \left\{p+c_{L}, \mu\left(p+c_{H}\right)+(1-\mu)\left(p-c_{1}\right)\right\}
$$

is the equilibrium utility to country 1 of the one-shot ultimatum game with prior $\mu$.

Let $r\left(x_{1}\right)$ be the probability that country 1 chooses to renegotiate after an offer $x_{1}$ has been accepted. As the payoff of renegotiating is no higher than $\delta\left(p+c_{H}\right)$ and no lower than $\delta\left(p+c_{L}\right)$, it follows that in every equilibrium $r\left(x_{1}\right)=0$ for all $x_{1}>\delta\left(p+c_{H}\right)$ and $r\left(x_{1}\right)=1$ for all $x_{1}<\delta\left(p+c_{L}\right)$.

Our first result is a simple consequence of incentive compatibility.

Lemma 1. Assume $\delta<1$. In every strong PBE of game $G_{A}$, if $2 L$ plays accept with positive probability in response to some offer $x_{1}$, then $2 H$ must accept $x_{1}$ with probability one.

Proof. In order for accept to be a best response to $x_{1}$ for $2 L$, we must have

$$
\begin{gathered}
r\left(x_{1}\right) \delta\left(p_{2}-c_{L}\right)+\left(1-r\left(x_{1}\right)\right)\left(1-x_{1}\right) \geq p_{2}-c_{L} \\
\left(1-r\left(x_{1}\right)\right)\left(1-x_{1}\right) \geq\left(1-r\left(x_{1}\right) \delta\right)\left(p_{2}-c_{L}\right) .
\end{gathered}
$$

On the other hand, the minimum payoff for $2 H$ for accepting is $r\left(x_{1}\right) \delta\left(p_{2}-c_{H}\right)+(1-$ $\left.r\left(x_{1}\right)\right)\left(1-x_{1}\right)$. Therefore $2 H$ must accept with probability one when

$$
\begin{gathered}
r\left(x_{1}\right) \delta\left(p_{2}-c_{H}\right)+\left(1-r\left(x_{1}\right)\right)\left(1-x_{1}\right)>p_{2}-c_{H} \\
\left(1-r\left(x_{1}\right)\right)\left(1-x_{1}\right)>\left(1-r\left(x_{1}\right) \delta\right)\left(p_{2}-c_{H}\right) .
\end{gathered}
$$

As $c_{L}<c_{H}$, it is clear that the inequality for $2 L$ implies the inequality for $2 H$. This establishes the lemma.

So if the low-cost type is not fighting for sure, then the high-cost type must be accepting for sure. We are now ready to prove the proposition.

Proof. Consider an arbitrary offer $x_{1}$. For $2 L$, accepting this offer will either be agreed to or play will move to period 2. Therefore accepting this offer will give a payoff no larger than $\max \left\{1-x_{1}, \delta\left(1-p-c_{L}\right)\right\}$. It follows that $2 L$ will choose fight in response to every offer such 
that $1-p-c_{L}>1-x_{1}$, which is equivalent to $x_{1}>p+c_{L}$. For $x_{1}<\delta\left(p+c_{L}\right)$ we know that $r\left(x_{1}\right)=1$ and so $2 L$ strictly prefers to fight. For $2 H$, because $r\left(x_{1}\right)=0$ for all $x_{1}>\delta\left(p+c_{H}\right)$, it follows that $2 H$ strictly prefers to fight for all $x_{1}>p+c_{H}$ and strictly prefers to accept for all $x_{1} \in\left(\delta\left(p+c_{H}\right), p+c_{H}\right)$. From this, we see that the utility to country 1 of making an offer $x_{1}>p+c_{H}$ is $p-c_{1}$. On the other hand, for all offers $x_{1} \in\left(\max \left\{\delta\left(p+c_{H}\right), p+c_{L}\right\}, p+c_{H}\right)$, the above implies that the utility to country 1 is $q x_{1}+(1-q)\left(p-c_{1}\right)$. In particular, this means that country 1 can achieve a payoff arbitrarily close to $q\left(p+c_{H}\right)+(1-q)\left(p-c_{1}\right)$. It follows that it cannot be an equilibrium for country 1 to make an offer $x_{1}>p+c_{H}$. In addition, no offer $x_{1} \in\left(\max \left\{\delta\left(p+c_{H}\right), p+c_{L}\right\}, p+c_{H}\right)$ can be optimal, as country 1 can deviate to a slightly higher offer and improve its payoff.

Next we show that it cannot be an equilibrium for country 1 to offer $x_{1} \leq \max \{\delta(p+$ $\left.\left.c_{H}\right), p+c_{L}\right\}$. We consider two cases. First, suppose $\delta\left(p+c_{H}\right)>p+c_{L}$. Then for all $x_{1} \in\left(p+c_{L}, \delta\left(p+c_{H}\right)\right], 2 L$ is fighting with probability one, so the maximum possible utility to country 1 is $q \delta\left(p+c_{H}\right)+(1-q)\left(p-c_{1}\right)$ which cannot be optimal. For $x_{1} \leq p+c_{L}$, if $2 L$ is fighting with probability one then the preceding argument still holds. Otherwise, $2 L$ is accepting with positive probability, which by Lemma 1 implies $2 H$ is accepting with probability one and country 1 either renegotiates or agrees. If it renegotiates, its highest possible payoff is again $q \delta\left(p+c_{H}\right)+(1-q)\left(p-c_{1}\right)$, and if it agrees, its highest possible payoff is $x_{1} \leq p+c_{L}$, which, given $q>q^{*}$, is strictly less than $q\left(p+c_{H}\right)+(1-q)\left(p-c_{1}\right)$. So no such offer can be optimal.

The seconds case is $\delta\left(p+c_{H}\right) \leq p+c_{L}$. For all $x_{1} \leq p+c_{L}$, if $2 L$ is fighting with probability one, then the maximum possible utility to country 1 is $q\left(p+c_{L}\right)+(1-q)\left(p-c_{1}\right)$ which cannot be optimal. Otherwise $2 L$ is accepting with positive probability, which by Lemma 1 implies $2 H$ is accepting with probability one and country 1 either renegotiates or agrees. If it renegotiates, its highest possible payoff is $q \delta\left(p+c_{H}\right)+(1-q)\left(p-c_{1}\right)$, and if it agrees, its highest possible payoff is $x_{1} \leq p+c_{L}$, which, given $q>q^{*}$, is strictly less than $q\left(p+c_{H}\right)+(1-q)\left(p-c_{1}\right)$. So no such offer can be optimal.

From this we conclude that the only possible equilibrium offer is $x_{1}=p+c_{H}$ which $2 L$ rejects and, by standard arguments, $2 H$ accepts with probability one. It is clear that country 1 will agree with this acceptance. This proves the Proposition.

Although the equilibrium path of play in this model is unique, the equilibrium strategies are not unique. In particular, for some offers, there are several strategies that are consistent with equilibrium. For example, suppose $\delta\left(p+c_{H}\right)>p+c_{L}$ and consider the offer $x_{1}=$ $\delta\left(p+c_{H}\right)$. From the above, we know $2 L$ will fight in response to this offer. It is easy to 
see that it is sequentially rational for $2 H$ to accept this offer and for country 1 to agree. But there are also mixed strategies consistent with equilibrium. As long as $2 H$ accepts with positive probability, country 1 believes country 2 is the high type and will offer $x_{2}=p+c_{H}$, which country 1 expects to be accepted. Therefore country 1 is indifferent between agreeing and renegotiating. Indeed, it is consistent with equilibrium for $2 H$ to accept with probability one and country 1 to mix with probability $r \leq p+c_{H}$. In fact, if country 1 plays $r \leq p+c_{H}$, type $2 H$ is indifferent between accepting and fighting and it is consistent with equilibrium for $2 H$ to arbitrarily mix between these two choices.

It is also true that, while the equilibrium outcome is the same as for a one-shot ultimatum game, the behavior for non-equilibrium offers can be very different than the equilibrium behavior in the ultimatum game. For example, the following is a PBE to this game. Country 1 offers $x_{1}=p+c_{H}$, chooses $r\left(x_{1}\right)=1$ for all $x_{1}<\delta\left(p+c_{H}\right)$ and $r\left(x_{1}\right)=0$ for all $x_{1} \geq \delta\left(p+c_{H}\right)$, and chooses $x_{2}\left(x_{1}\right)=p+c_{H}$ for all $x_{1}$. Type $2 L$ fights in response to every $x_{1}$ and type $2 H$ fights in response to every $x_{1}<\delta\left(p+c_{H}\right)$ and to every $x_{1}>p+c_{H}$ and accepts in response to every $x_{1} \in\left[\delta\left(p+c_{H}\right), p+c_{H}\right]$. One notable feature of this equilibrium is that $2 L$ rejects all offers and both $2 H$ and $2 L$ reject generous offers $\left(x_{1}<\delta\left(p+c_{H}\right)\right)$. The intuition for this is that accepting a generous offer will not be agreed to by country 1 (it is too generous!), but renegotiation is always worse for both types than fighting in the first period.

When $\delta$ is equal to one, the set of equilibrium outcomes expands. For example, when $\delta=1$ we can give examples of PBE in which both types of country 2 choose to fight with probability one and also examples in which the outcome is fighting with some probability and agreement on the one-shot ultimatum offer with the remaining probability. That these kinds of equilibria exist may be surprising as one could imagine a profitable deviation for the proposer of making a slightly more generous offer which would typically be accepted with probability one. But with costless renegotiation (due to $\delta=1$ ), such an offer by country 1 is not credible as following acceptance country 1 would renegotiate. How big is the set of equilibria when $\delta=1$ ? In fact, fighting and agreement on $p+c_{H}$ are the only possible outcomes that can occur in equilibrium. In other words, there are no strong PBE in which agreement occurs (with positive probability) on an offer other than the one-shot ultimatum offer.

Proposition 2. Assume $q>q^{*}$ and $\delta=1$. Then the support of equilibrium outcomes of strong PBE of game $G_{A}$ is fighting and agreement on $x=p+c_{H}$.

Proof. We must show that if a peaceful agreement is reached with positive probability in 
equilibrium, then this agreement will be at $x=p+c_{H}$. So, to begin, take an arbitrary offer $x_{1}$ and assume this offer is agreed to with positive probability by some type of country 2 and country 1 chooses renegotiation with positive probability in an equilibrium. (Note we do not require that $x_{1}$ be the equilibrium offer of country 1.) We will show that country 1 will offer $x_{2}=p+c_{H}$ for sure in the second period. Suppose not, that is, country 1 offers $x_{2}=p+c_{L}$ with positive probability. First, note that if country 1 is choosing renegotiation with positive probability, it must be that $x_{1} \leq p+c_{H}$. Second, note that by agreeing to $x_{1}$, type $2 H$ will receive $1-x_{1} \geq 1-p-c_{H}$ with probability less than one, when country 1 chooses to agree, and when country 1 chooses to renegotiate, receives $1-p-c_{L}$ with positive probability because $x_{2}=p+c_{L}$ with positive probability by supposition, and $1-p-c_{H}$ with the remaining probability. As this expected utility is strictly greater than $1-p-c_{H}$, type $2 H$ will agree to $x_{1}$ with probability one. But then by Bayes' Rule, $\mu_{A}\left(x_{1}\right) \geq q>q^{*}$ and so country 1 will choose $x_{2}=p+c_{H}$ with certainty in period 2. This establishes that if agreement is reached with positive probability in the second period, it must be at $x=p+c_{H}$.

The only other possibility is that there is agreement in the first period. So suppose $\tilde{x}_{1}$ is the equilibrium offer of country 1 which is accepted with positive probability by some type and country 1 agrees to this acceptance with positive probability. The above result shows that if country 1 is not agreeing with probability one, then $x_{2}=p+c_{H}$ will be offered in the second period. From this, we see that if $\tilde{x}_{1}$ is greater than $p+c_{H}$, then for both types of country 2 accepting gives a positive probability of utility $1-\tilde{x}_{1}$ and the remaining probability of utility $1-p-c_{H}$, which is strictly worse than the utility for fighting for both types. Therefore it must be that $\tilde{x}_{1} \leq p+c_{H}$. On the other hand, suppose $\tilde{x}_{1}<p+c_{H}$. Then as acceptance is agreed to with positive probability, it is clear that $2 H$ must be accepting $\tilde{x}_{1}$ with probability one. If $\tilde{x}_{1} \in\left(p+c_{L}, p+c_{H}\right)$, then clearly $2 L$ will choose fight with probability one in the first period, but then it is optimal for country 1 to renegotiate with probability one instead of agreeing with positive probability. If $\tilde{x}_{1} \leq p+c_{L}$, then highest possible payoff of agreeing is $p+c_{L}$ which is smaller than the payoff of renegotiating, because country 1's belief in the second period will be strictly greater than $q^{*}$. So again, this contradicts the assumption that country 1 is agreeing with positive probability. We conclude therefore that $\tilde{x}_{1}=p+c_{H}$, which concludes the proof. 


\section{No Commitment to Fighting}

We now examine what happens when we relax the commitment assumptions of the baseline model in a different way. We suppose that agreements are binding, but rejecting an offer can lead to continued bargaining. Specifically, in this game country 1 makes an initial offer $x_{1} \in[0,1]$ in period 1 , which country 2 either accepts or rejects. If the offer is accepted by country 2 , then countries 1 and 2 receive payoffs of $x_{1}$ and $1-x_{1}$, respectively. If country 2 rejects the offer, then country 1 can either decide to end the bargaining and fight, which gives each side its war payoff $p_{i}-c_{i}$, or to move the game to a second period of bargaining, in which the payoff to both sides is discounted by a factor $\delta \in(0,1)$. Specifically, following a rejection by country 2 in the first period and a decision by country 1 to continue to the second period country 1 makes an offer $x_{2} \in[0,1]$, which country 2 either accepts or rejects. If the offer is accepted by country 2 , then countries 1 and 2 receive payoffs of $\delta x_{2}$ and $\delta\left(1-x_{2}\right)$, respectively. If country 2 rejects the offer, then war ensues and each country $i$ receives its (discounted) war payoff, which is given by $\delta\left(p_{i}-c_{i}\right)$. This game, in which agreements are binding but rejections can be renegotiated, is illustrated in Figure 2. We refer to this game as game $G_{R}$.

Recall that $q^{*}=\left(c_{1}+c_{L}\right) /\left(c_{1}+c_{H}\right)$ and $v_{1}^{*}(\mu)=\max \left\{p+c_{L}, \mu\left(p+c_{H}\right)+(1-\mu)\left(p-c_{1}\right)\right\}$. We let $x_{L}^{*}=1-\delta\left(1-p-c_{L}\right)$ and $x_{H}^{*}=1-\delta\left(1-p-c_{H}\right)$. It is clear that $0<x_{L}^{*}<x_{H}^{*}<1$. We also let

$$
\delta^{*}=\max \left\{\frac{1-q}{1-q+\left(q-q^{*}\right)\left(c_{H}-c_{L}\right)}, \frac{p-c_{1}}{p+c_{L}}\right\} .
$$

As before, we describe some useful facts about the second period of this game. Let $\mu_{R}\left(x_{1}\right)$ denote the belief of country 1 about the type of country 2 in the second period, after an offer $x_{1}$ in the first period. Specifically, $\mu_{R}\left(x_{1}\right)=P\left[c_{2}=c_{H} \mid x_{1}\right.$ rejected], the probability that country 1 believes country 2 is the high cost type. As in the last section, we know that $x_{2}=p+c_{L}$ if $\mu_{R}<q^{*}, x_{2}=p+c_{H}$ if $\mu_{R}>q^{*}$, and country 1 is indifferent between making these two offers if $\mu_{R}=q^{*}$. Moreover, if $x_{2}=p+c_{L}$ in equilibrium, then both types of country 2 accept this offer with probability one, and if $x_{2}=p+c_{H}$ in equilibrium, then $2 H$ accepts with probability one and $2 L$ rejects with probability one. Finally, whatever value $\mu_{R}$ takes, the (undiscounted) payoff to $2 L$ in period 2 is $1-p-c_{L}$. Moreover, the (undiscounted) payoff to $2 H$ is in the interval $\left[1-p-c_{H}, 1-p-c_{L}\right]$. Likewise, the (undiscounted) payoff to country 1 is $v_{1}^{*}\left(\mu_{R}\left(x_{1}\right)\right)$.

The following proposition characterizes the unique (strong) PBE of this game. 


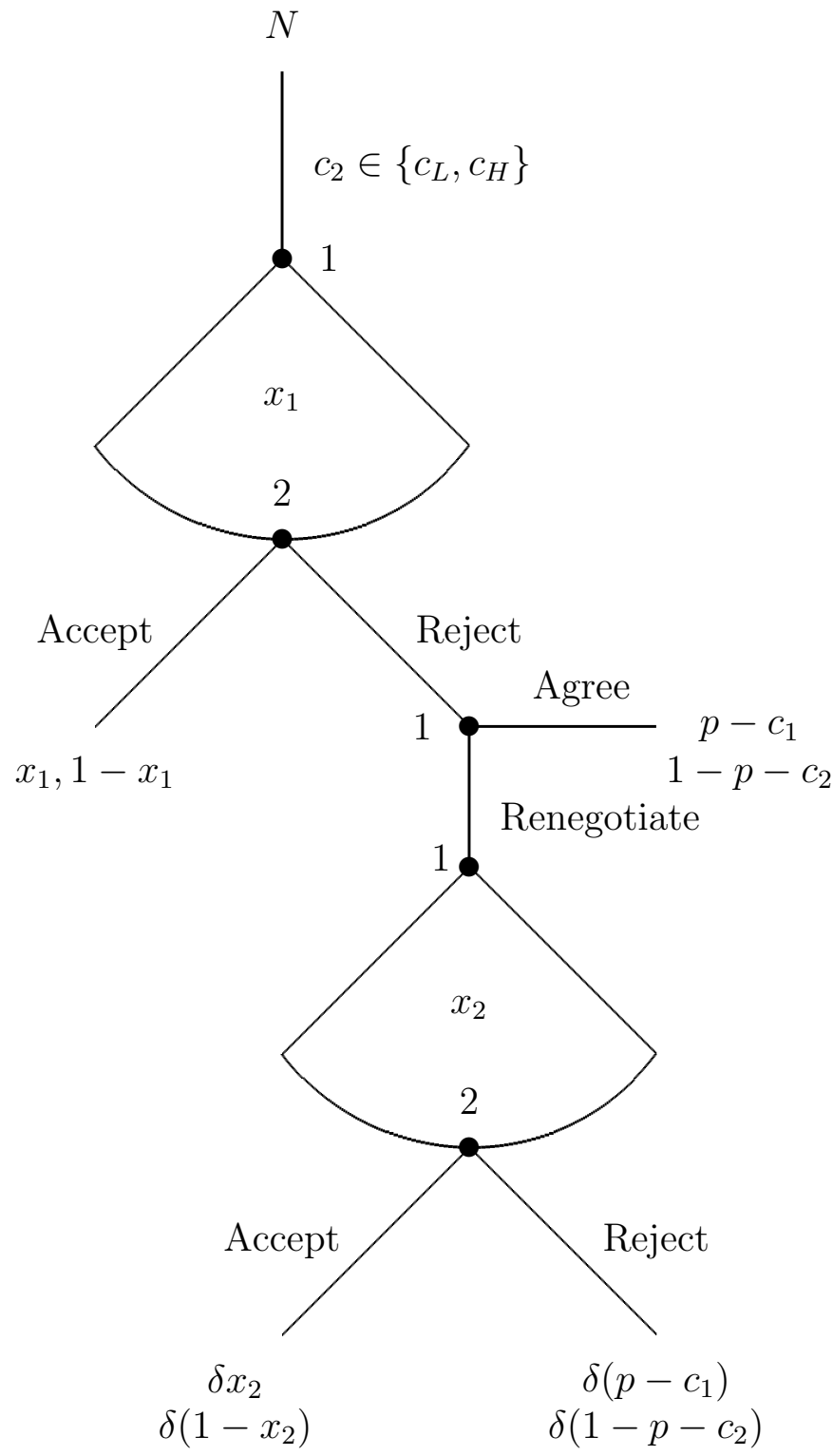

Figure 2: The game $G_{R}$, with no commitment to fighting 
Proposition 3. Suppose $q>q^{*}$ and $\delta>\delta^{*}$. Then there exists a unique (strong) PBE to game $G_{R}$. The equilibrium path of play is given by $x_{1}=x_{H}^{*}$, which is rejected by the low cost type and which the high cost type mixes between accepting and rejecting. Country 1 chooses to continue bargaining and offers $x_{2}=p+c_{H}$. Only the high cost type accepts this offer.

Proof. Consider the decision of country 1 after an arbitrary offer $x_{1}$ has been rejected. Given country 1's belief $\mu_{R}\left(x_{1}\right)$ at this point in the game, its payoff from continuing to bargain is $\delta v_{1}^{*}\left(\mu_{R}\left(x_{1}\right)\right) \geq \delta\left(p+c_{L}\right)$. By choosing to fight at this point, however, country 1 receives a payoff of $p-c_{1}$. Given our condition on $\delta$, we know that $\delta\left(p+c_{L}\right)>p-c_{1}$. Therefore, it is never optimal for country 1 to fight after an offer has been rejected. In other words, in every perfect Bayesian equilibrium, country 1 always continues bargaining rather than fighting, regardless of the initial offer $x_{1}$.

Now we turn to period 1 . Consider an arbitrary offer $x_{1}$. For $2 L$, rejecting this offer gives a payoff of $\delta\left(1-p-c_{L}\right)$. Therefore, $2 L$ will reject any offer such that $1-x_{1}<\delta\left(1-p-c_{L}\right)$, which is equivalent to $x_{1}>x_{L}^{*}$, and will accept any offer such that $x_{1}<x_{L}^{*}$. For $2 H$, because rejecting this offer gives a payoff of at most $\delta\left(1-p-c_{L}\right), 2 H$ will also accept any offer such that $x_{1}<x_{L}^{*}$. On the other hand, because rejecting this offer gives $2 H$ a payoff of at least $\delta\left(1-p-c_{H}\right), 2 H$ will reject any offer such that $x_{1}>x_{H}^{*}$. Because both types of country 2 accept any offer $x_{1}<x_{L}^{*}$, in any PBE the payoff to country 1 satisfies $u_{1}^{*}\left(x_{1}\right)=x_{1}$ for all $x_{1} \in\left[0, x_{L}^{*}\right)$. An immediate consequence of this is that there is no PBE in which country 1 makes such an offer with positive probability.

In any strong perfect Bayesian equilibrium, the belief of country 1 must be derived via Bayes' Rule from the sequentially rational response of country 2 to a given offer, whether this offer is on or off the equilibrium path. Thus, as both types of country 2 reject any offer $x_{1}>x_{H}^{*}$, in any strong perfect Bayesian equilibrium $\mu_{R}\left(x_{1}\right)=q$. This implies that in any strong PBE, $u_{1}^{*}\left(x_{1}\right)=\delta v_{1}^{*}(q)$ for all $x_{1} \in\left(x_{H}^{*}, 1\right]$.

Next, consider an offer $x_{1} \in\left(x_{L}^{*}, x_{H}^{*}\right)$. From above, $2 L$ rejects this offer. We claim that $2 H$ must play a mixed strategy in response to this offer. If $2 H$ rejects $x_{1}$ with probability one, then $\mu_{R}\left(x_{1}\right)=q$ and because $q>q^{*}, x_{2}=p+c_{H}$. This gives $2 H$ a payoff of $1-x_{H}^{*}$. But then deviating to accepting $x_{1}$ gives a payoff strictly greater than $1-x_{H}^{*}$, so this cannot be an equilibrium. If $2 H$ accepts $x_{1}$ with probability one, then $\mu_{R}\left(x_{1}\right)=0$ and therefore $x_{2}=p+c_{L}$. So deviating to rejecting $x_{1}$ gives a payoff of $1-x_{L}^{*}$, which is strictly greater than $1-x_{1}$. Therefore this cannot be an equilibrium. So $2 H$ must play a mixed strategy.

In order to calculate this mixed strategy, let $s\left(x_{1}\right)$ be the probability that $2 H$ accepts $x_{1} \in\left(x_{L}^{*}, x_{H}^{*}\right)$. In order to make $2 H$ indifferent between accepting and rejecting $x_{1}$, country 1 
must mix between $x_{2}=p+c_{L}$ and $x_{2}=p+c_{H}$. So let $r\left(x_{1}\right)$ be the probability that country 1 makes the offer $x_{2}=p+c_{L}$ after offering $x_{1}$ in the first period. In order to ensure that $2 H$ is indifferent, we must have

$$
1-x_{1}=r\left(x_{1}\right) \delta\left(1-p-c_{L}\right)+\left(1-r\left(x_{1}\right)\right) \delta\left(1-p-c_{H}\right) .
$$

Solving this linear equation gives the following unique solution:

$$
r\left(x_{1}\right)=\frac{1-\delta\left(1-p-c_{H}\right)-x_{1}}{\delta\left(c_{H}-c_{L}\right)}=\frac{x_{H}^{*}-x_{1}}{\delta\left(c_{H}-c_{L}\right)} .
$$

In order for country 1 to be willing to mix in period 2, it must be indifferent between offering $x_{2}=p+c_{L}$ and $x_{2}=p+c_{H}$. This requires that $\mu_{R}=q^{*}$. From Bayes's Rule we know the belief $\mu_{R}$ is given by

$$
\mu_{R}=\frac{q\left(1-s\left(x_{1}\right)\right)}{q\left(1-s\left(x_{1}\right)\right)+(1-q)}=\frac{q-q s\left(x_{1}\right)}{1-q s\left(x_{1}\right)}
$$

and this allows us to solve for $s\left(x_{1}\right)$, which is given by

$$
s\left(x_{1}\right)=\frac{q-q^{*}}{q\left(1-q^{*}\right)} .
$$

It is easy to see that $s\left(x_{1}\right) \in(0,1)$ and, in fact, $s\left(x_{1}\right)$ is independent of $x_{1}$.

Given this unique mixed strategy, we can calculate the expected utility of country 1 making an offer $x_{1} \in\left(x_{L}^{*}, x_{H}^{*}\right)$. This utility is given by

$$
\begin{aligned}
u_{1}^{*}\left(x_{1}\right) & =q s\left(x_{1}\right) x_{1}+\left((1-q)+q\left(1-s\left(x_{1}\right)\right)\right) \delta\left(p+c_{L}\right) \\
& =\frac{x_{1}\left(q-q^{*}\right)+\delta(1-q)\left(p+c_{L}\right)}{1-q^{*}} .
\end{aligned}
$$

As $q>q^{*}$, we see that $u_{1}^{*}\left(x_{1}\right)$ is linearly increasing in $x_{1}$. A direct implication of this is that there is no PBE in which country 1 puts positive probability on any $x_{1} \in\left(x_{L}^{*}, x_{H}^{*}\right)$.

Next, consider an offer $x_{1}>x_{H}^{*}$. As both types of country 2 will reject this offer, the utility to country 1 of making this offer is

$$
u_{1}^{*}\left(x_{1}\right)=\delta v_{1}^{*}(q)=\delta\left[(1-q)\left(p-c_{1}\right)+q\left(p+c_{H}\right)\right] .
$$


Although we omit the details, it is possible to show algebraically that

$$
\frac{x_{H}^{*}\left(q-q^{*}\right)+\delta(1-q)\left(p+c_{L}\right)}{1-q^{*}}-u_{1}^{*}\left(x_{1}\right)=\frac{(1-\delta)\left(q-q^{*}\right)}{1-q^{*}} .
$$

As $q>q^{*}$, this shows that there exists a value $x_{1}^{\prime}<x_{H}^{*}$ sufficiently close to $x_{H}^{*}$ that gives country 1 a payoff strictly greater than $u_{1}^{*}\left(x_{1}\right)$. Therefore, there is no PBE in which country 1 puts positive probability on $x_{1}>x_{H}^{*}$.

By process of elimination, the only two remaining possibilities are $x_{1}=x_{L}^{*}$ and $x_{1}=x_{H}^{*}$. Consider the offer $x_{1}=x_{H}^{*}$. Of course, $2 L$ rejects this offer. If country 1 offers $x_{2}=p+c_{L}$ in the second period, then $2 H$ will strictly prefer to reject $x_{1}$ as well. This implies $\mu_{R}=q>q^{*}$, so country 1 strictly prefers to offer $x_{2}=p+c_{H}$. This argument shows that country 1 must play $x_{2}=p+c_{H}$ with positive probability after $x_{1}=x_{H}^{*}$. This requires that $\mu_{R}\left(x_{H}^{*}\right) \geq q^{*}$. This in turn implies that the probability that $2 H$ accepts $x_{1}=x_{H}^{*}$, which is denoted $s^{*}$, must satisfy $s^{*} \geq\left(q-q^{*}\right) /\left(q\left(1-q^{*}\right)\right)$. Moreover, if $x_{1}=x_{H}^{*}$ is played with positive probability in equilibrium, we must have $u_{1}^{*}\left(x_{H}^{*}\right) \geq u_{1}^{*}\left(x_{1}\right)$ for all $x_{1} \in\left(x_{L}^{*}, x_{H}^{*}\right)$. This requires that

$$
s^{*}=\frac{q-q^{*}}{q\left(1-q^{*}\right)} .
$$

In order for $2 H$ to be indifferent between accepting and rejecting $x_{1}=x_{H}^{*}$, it must be that $x_{2}=p+c_{H}$ with probability one. We conclude that

$$
u_{1}^{*}\left(x_{H}^{*}\right)=\frac{x_{H}^{*}\left(q-q^{*}\right)+\delta(1-q)\left(p+c_{L}\right)}{1-q^{*}}
$$

if this offer is played with positive probability. In order for this offer to be an equilibrium, $u_{1}^{*}\left(x_{H}^{*}\right) \geq u_{1}^{*}\left(x_{1}\right)$ for all $x_{1}<x_{L}^{*}$. As the highest possible payoff from $x_{1}=x_{L}^{*}$ is the limit of $u_{1}^{*}\left(x_{1}\right)$ as $x_{1} \rightarrow x_{L}^{*}$, this condition insures there is no profitable deviation to $x_{1}=x_{L}^{*}$, as well. This condition is satisfied if and only if

$$
\frac{x_{H}^{*}\left(q-q^{*}\right)+\delta(1-q)\left(p+c_{L}\right)}{1-q^{*}} \geq x_{L}^{*}
$$

Again we omit the details, but this inequality holds when

$$
\delta \geq \frac{1-q}{1-q+\left(q-q^{*}\right)\left(c_{H}-c_{L}\right)}=\delta^{*} .
$$

So for all $\delta>\delta^{*}$, there exists a unique strong PBE in which country 1 makes the offer 
$x_{1}=x_{H}^{*}$.

The key feature of this result is that agreement does not necessarily occur immediately. The high cost type of country 2 sometimes accepts country 1's initial offer and sometimes delays and accepts the offer in the second round. The low cost type of country 2 , on the other hand, rejects both offers and ends up in war, as in the baseline model with commitment. Indeed, although the exact value of the offers made differs from the baseline model, the main intuitions carry over. Country 1 makes demanding offers in both periods and ends up with peaceful agreements with high cost types of country 2 and war with low cost types. Upon closer examination, we see that the differences, such as they are, are driven by the ability of country 1 to delay war until the second period, which lowers the bargaining leverage inherent in rejecting offers. In support of this, we see that as $\delta$ goes to one, the offers of country 1 in both periods converge to the standard screening offer $x=p+c_{H}$.

\section{No Commitment to Agreement or Rejection}

Finally we consider the case where there is neither commitment to enact accepted proposals or to fight when an offer is rejected. In this case, a choice by country 2 to either accept or reject can be renegotiated by country 1 . However, we do permit country 2 to make a third choice of fighting which cannot be renegotiated by country 1 . We are interested in how the equilibria outcomes of this more general game relate to the equilibria outcomes of the models presented in the earlier sections.

We will denote the version of the game without commitment to agreeing or rejection by $G_{A R}$. In this version of the game, country 1 makes an initial offer $x_{1} \in[0,1]$ in period 1 . Country 2 responds by choosing accept, reject, or fight. If country 2 chooses to fight, war ensues and both sides receive its war payoff $p_{i}-c_{i}$. If the offer is accepted by country 2 , then country 1 can either agree, in which case the two sides receive payoffs of $x_{1}$ and $1-x_{1}$, respectively, or country 1 can choose to renegotiate, which moves the game to a second round of bargaining. Finally, if country 2 rejects the offer, then country 1 can either decide to end the bargaining and fight, which gives each side its war payoff, or to move the game to a second period of bargaining. In the second round, the payoff to both sides is discounted by a factor $\delta \in(0,1)$. Specifically, country 1 makes an offer $x_{2} \in[0,1]$, which country 2 either accepts or rejects. If the offer is accepted by country 2 , then countries 1 and 2 receive payoffs of $\delta x_{2}$ and $\delta\left(1-x_{2}\right)$, respectively. If country 2 rejects the offer, then war ensues and each 
country $i$ receives its (discounted) war payoff, which is given by $\delta\left(p_{i}-c_{i}\right)$. So in this version of the model, either acceptance or rejection can be countered with a new offer, but fighting leads to immediate war. We illustrate game $G_{A R}$ in Figure 3.

We begin with the following useful lemma

Lemma 2. Suppose $\delta<1$. In every equilibrium of the game $G_{A R}$, if some type of country 2 rejects an offer $x_{1}$ with positive probability, then country 1 responds to this rejection by fighting with probability one.

Proof. Let $\sigma^{*}$ be an equilibrium of $G_{A R}$ in which after an offer $x_{1}$, some type rejects this offer with positive probability. Let $c_{m}$ be equal to $c_{L}$ if this type rejects $x_{1}$ with positive probability, otherwise let $c_{m}$ be equal to $c_{H}$. By standard ultimatum game arguments, in the second period, country 1 will make an offer to country 2 that is no smaller than the war payoff of type $c_{m}$ of country 2 , so that $1-x_{2} \leq p_{2}-c_{m}$. So the maximum payoff achievable by type $c_{m}$ in the second period is $\delta\left(p_{2}-c_{m}\right)$. Now, moving back to country 1's decision on whether to renegotiate or fight after country 2's rejection, let $q_{F}$ be the probability that country 1 fights. Then the utility of type $c_{m}$ of country 2 for rejecting is $q_{F}\left(p_{2}-c_{m}\right)+\left(1-q_{F}\right) \delta\left(p_{2}-c_{m}\right)$. As $p_{2}>c_{m}$ and $\delta<1$, this payoff is strictly less than $p_{2}-c_{m}$ for all $q_{F}<1$. But in order for rejecting to be played with positive probability by type $c_{m}$, it must be at least as good as fighting, which gives a payoff of $p_{2}-c_{m}$. This establishes that $q_{F}=1$.

For games $G_{A}$ and $G_{A R}$, the outcome of a strategy profile is a probability distribution over fighting in periods one and two and the terms of settlement in periods one and two. In other words, the outcome is defined over terminal nodes where all "fight" terminal nodes in a given period are grouped together and all "peaceful settlement" with given terms in a given period are grouped together. Our main result is that viewed this way, the model with no commitment to either agreements or rejection has the same equilibrium distribution of outcomes as the baseline ultimatum game model.

Proposition 4. For all $\delta<1$, the unique equilibrium distribution of outcomes of $G_{A R}$ is equal to the one-shot ultimatum game.

Proof. As game $G_{A}$ has a unique distribution of equilibrium outcomes, which is equal to the one-shot ultimatum game, it is enough to show that every equilibrium outcome of $G_{A R}$ is an equilibrium outcome of $G_{A}$. Suppose $\sigma^{*}$ is an equilibrium of $G_{A R}$. We will construct an equilibrium $\sigma^{\prime}$ of $G_{A}$ that has an identical outcome. To begin, consider an arbitrary offer $x_{1}$ by country 1 in the first period. If neither type chooses to reject this offer (with positive 


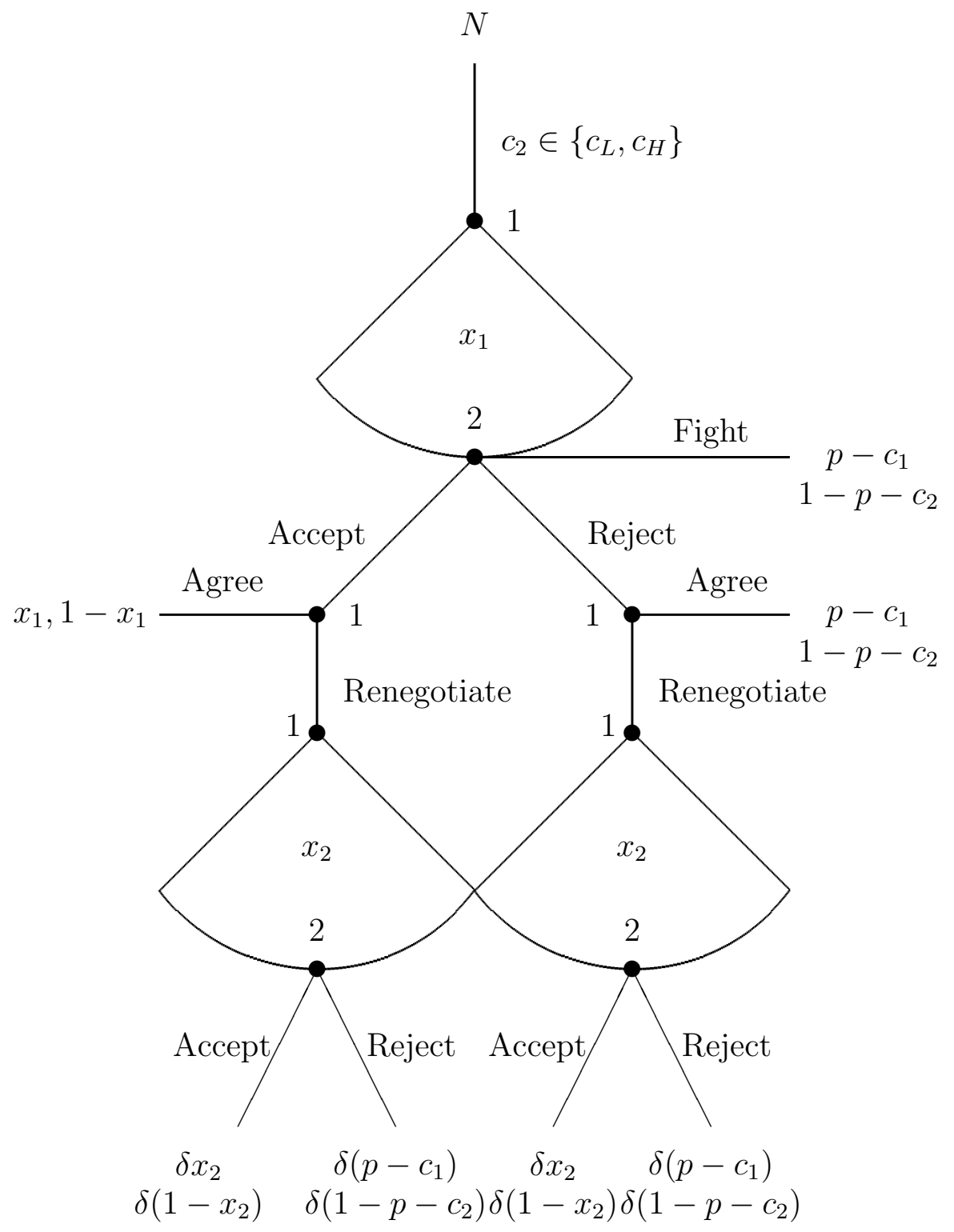

Figure 3: The game $G_{A R}$, with no commitment 
probability), then the construction of $\sigma^{\prime}$ is simple; it is equal to $\sigma^{*}$. As it is optimal for all types to either play accept or fight under $\sigma^{*}$, it is still optimal for these types to take these same actions when the reject option is unavailable. Clearly, the outcome of $G_{A R}$ under $\sigma^{*}$ is identical to the outcome of $G_{A}$ under $\sigma^{\prime}$.

The other possibility is that some type rejects the offer $x_{1}$ with positive probability. In this case, $\sigma^{\prime}$ is equal to $\sigma^{*}$ for the type (if any) that does not play reject with positive probability and $\sigma^{\prime}$ is equal to the fight action in period one for all types that do reject with positive probability under $\sigma^{*}$. To see that $\sigma^{\prime}$ represents equilibrium play, we use Lemma 2 to note that the equilibrium outcome of every type that is rejecting under $\sigma^{*}$ is fighting in period 1 . Therefore these types receive the same utility under $\sigma^{\prime}$ by choosing the fight action instead. For those types who are not rejecting under $\sigma^{*}$, since a possible deviation to reject gives the same utility as choosing to fight, there is no change in equilibrium incentives for these types when the reject option is removed. Therefore $\sigma^{\prime}$ represents optimal behavior in $G_{A}$. Moreover, the outcome for the types in who reject under $\sigma^{*}$ is fighting in period 1 and by construction the outcome in $G_{A}$ for these types under $\sigma^{\prime}$ is also fighting in period 1 . This shows that the outcome of $G_{A R}$ under $\sigma^{*}$ is identical to the outcome of $G_{A}$ under $\sigma^{\prime}$.

We conclude that for all offers $x_{1}$, the outcome of $G_{A R}$ under $\sigma^{*}$ is identical to the outcome of $G_{A}$ under $\sigma^{\prime}$. Therefore the optimal choice of offer by country 1 must be the same in $\sigma^{*}$ and $\sigma^{\prime}$ and so every equilibrium outcome of $G_{A R}$ is an equilibrium outcome of $G_{A}$.

\section{Results with a Continuum of Types}

While the intuition is clear in the two type case as to why there is no incentive to renegotiate in the short-run when there is no commitment to agreements, one might be concerned that the fact that country 1 only can make one of two proposals in equilibrium is driving the results. Perhaps the presence of more types and the possibility for a continuum of complete information equilibrium offers might change the results. Thus, in order to see how robust our results are, we next analyze the case with a continuum of cost types.

Suppose $c_{2}$ is distributed according to a differentiable and strictly increasing cumulative distribution function $F$ with support $[0,1-p]$ and density function $f$. In the one-shot ultimatum game, it is easy to see that country 2 will reject an offer $x$ when $c_{2}<x-p$ and accept the offer when $c_{2}>x-p$. From this, it follows that the utility to country 1 of making 
an offer $x$, which we denote $v(x)$, is given by

$$
v(x)=F(x-p)\left(p-c_{1}\right)+(1-F(x-p)) x .
$$

The next lemma demonstrates that this function has a unique maximizer and gives a simple condition on when it is interior.

Lemma 3. If the hazard rate $f\left(c_{2}\right) /\left(1-F\left(c_{2}\right)\right)$ is nondecreasing, then $v(x)$ has a unique maximizer $x^{*}$. This maximizer $x^{*} \in(p, 1)$ if and only if $f(0)<1 / c_{1}$.

Proof. As the set of possible offers is $[0,1]$ and $v(x)$ is continuous on this set, a maximizer exists. It is clear from inspection that offering $x<p$ is not optimal. Likewise, it is clear that offering $x=1$ is not optimal. Now, the derivative of $v(x)$ can be written as

$$
v^{\prime}(x)=[1-F(x-p)]\left[1-h(x-p)\left(x-\left(p-c_{1}\right)\right)\right]
$$

where $h(x)=f(x) /(1-F(x))$ is the hazard rate. As $h(x-p)$ is nondecreasing and always positive on $[p, 1)$ and the term $x-\left(p-c_{1}\right)$ is strictly increasing and always positive on $[p, 1)$, the product of these two terms is strictly increasing on $[p, 1)$.

Now suppose $f(0) \geq 1 / c_{1}$. This is equivalent to $h(0) c_{1} \geq 1$ which is equivalent to $v^{\prime}(p) \leq 0$. Moreover, by the above we know that $h(x-p)\left(x-\left(p-c_{1}\right)\right)>1$ for all $x \in(p, 1)$ so $v^{\prime}(x)<0$ for all $\operatorname{such} x$. This establishes that $x^{*}=p$ is the unique maximizer of $v(x)$ in this case. On the other hand, suppose $f(0)<1 / c_{1}$, which is equivalent to $v^{\prime}(p)>0$ so $x=p$ is not a maximizer. Again, as $h(x-p)\left(x-\left(p-c_{1}\right)\right)$ is strictly increasing on $(p, 1)$, this term cannot be equal to 1 for more than one value of $x$. Therefore, there must exist a unique maximizer $x^{*} \in(p, 1)$. This proves the lemma.

This lemma implies that in the one-shot ultimatum game, there is a unique PBE in which country 1 offers $x^{*}$ and country 2 responds to this offer according to the cutpoint $c^{*}=x^{*}-p$. To avoid boundary cases, we assume throughout this section that $f(0)<1 / c_{1}$, so that the cutpoint $c^{*}$ is interior to the interval $[0,1-p]$.

\subsection{No Commitment to Agreements}

We begin with game $G_{A}$, in which country 1 can choose to renegotiate accepted offers. An arbitrary strong PBE can be described by the following: The equilibrium choice of $x_{1}$; for each possible offer $x_{1}$, the cutpoint $\hat{c}\left(x_{1}\right)$ such that country 2 rejects $x_{1}$ in the first period 
if $c_{2}<\hat{c}\left(x_{1}\right)$ and accepts $x_{1}$ if $c_{2}>\hat{c}\left(x_{1}\right)$; the probability $r\left(x_{1}\right)$ that country 1 chooses to renegotiate after $x_{1}$ is accepted, and the offer $x_{2}\left(x_{1}\right)$. Clearly, in equilibrium country 2 will reject $x_{2}\left(x_{1}\right)$ in the second period if $c_{2}<x_{2}\left(x_{1}\right)-p$ and accept if $c_{2}>x_{2}\left(x_{1}\right)-p$. Note that if $\hat{c}\left(x_{1}\right)$ is interior to the interval $[0,1-p]$, then this type of country 2 must be indifferent between accepting and rejecting the offer $x_{1}$. Finally, for country 1 , we let $u\left(x_{1}\right)$ be the utility of making the offer $x_{1}$ in a given PBE.

We begin our analysis by presenting two useful lemmas. To understand the intuition for the first lemma, recall that in the equilibrium outcome of the two type version of our model, country 1 did not change his offer in response to learning the true type of country 2 . A similar result holds in the case with continuous types. Specifically, we show that in the second period, country 1 will either offer $x^{*}$, the equilibrium offer in the one-shot ultimatum game, or the largest offer that country 1 believes will be accepted with certainty.

Lemma 4. Suppose the hazard rate $f\left(c_{2}\right) /\left(1-F\left(c_{2}\right)\right.$ is nondecreasing. Then in every strong PBE, $x_{2}\left(x_{1}\right)=\max \left\{x^{*}, p+\hat{c}\left(x_{1}\right)\right\}$ for all $x_{1}$ that are accepted with positive probability.

Proof. Fix a strong PBE and let $x_{1}$ be arbitrary. For clarity, we write $\hat{c}$ for $\hat{c}\left(x_{1}\right)$ and $x_{2}$ for $x_{2}\left(x_{1}\right)$. After observing that $x_{1}$ has been accepted, country 1's belief is given by $\hat{F}\left(c_{2}\right)$, with density equal to $g\left(c_{2}\right) /(1-F(\hat{c}))$, where $g(t)=f(t)$ on $[\hat{c}, 1-p]$ and 0 otherwise. Given this belief, country 1 expects all offers $x_{2} \leq p+\hat{c}$ will be accepted with probability one and so it cannot be optimal to offer $x_{2}<p+\hat{c}$. Therefore, country 1 solves the following constrained optimization problem:

$$
\begin{gathered}
\max _{x_{2}}\left[x_{2}\left(1-\hat{F}\left(x_{2}-p\right)\right)+\hat{F}\left(x_{2}-p\right)\left(p-c_{1}\right)\right] \\
\text { s.t. } \quad x_{2} \geq p+\hat{c} .
\end{gathered}
$$

This expression is equivalent to

$$
\begin{gathered}
\max _{x_{2}}\left[x_{2} \frac{\int_{x_{2}-p}^{1-p} g(t) d t}{1-F(\hat{c})}+\left(p-c_{1}\right) \frac{\int_{\underline{c}}^{x_{2}-p} g(t) d t}{1-F(\hat{c})}\right] \\
\text { s.t. } \quad x_{2} \geq p+\hat{c} .
\end{gathered}
$$

Ignoring the constraint for the moment, by Leibniz's rule we obtain the first order condition 
for the relaxed problem:

$$
\frac{\int_{x_{2}-p}^{1-p} g(t) d t}{1-F(\hat{c})}-\frac{x_{2} g\left(x_{2}-p\right)}{1-F(\hat{c})}+\left(p-c_{1}\right) \frac{g\left(x_{2}-p\right)}{1-F(\hat{c})}=0
$$

Returning to the constrained problem, there are two possibilities. First, if the constraint holds with equality at the maximizer, then the maximizer equals $p+\hat{c}$. Otherwise, if the constraint does not hold with equality at the maximizer, then the maximizer satisfies $x_{2}-p>$ $\hat{c}$ and solves the first order condition of the relaxed problem. As $x_{2}-p>\hat{c}$, this condition simplifies to

$$
1-F\left(x_{2}-p\right)-x_{2} f\left(x_{2}-p\right)+\left(p-c_{1}\right) f\left(x_{2}-p\right)=0 .
$$

But this is precisely the first order condition for $v(x)$ and therefore the maximizer must equal $x^{*}$. This proves the result.

Our second lemma gathers some necessary conditions for equilibria in our model.

Lemma 5. Suppose the hazard rate $f\left(c_{2}\right) /\left(1-F\left(c_{2}\right)\right.$ is nondecreasing and $\delta<1$. Then in every strong PBE, the following are true:

1. $r\left(x_{1}\right)<1$ for all $x_{1}$ that are accepted with positive probability,

2. $\hat{c}\left(x_{1}\right) \geq x_{1}-p$ for all $x_{1}$,

3. $x_{2}\left(x_{1}\right) \geq x_{1}$ for all $x_{1}$ that are accepted with positive probability,

4. $u\left(x_{1}\right)=F\left(\hat{c}\left(x_{1}\right)\right)\left(p-c_{1}\right)+\left(1-F\left(\hat{c}\left(x_{1}\right)\right)\right) x_{1}$ for all $x_{1}$, and

5. $u\left(x_{1}\right) \leq v\left(x_{1}\right)$ for all $x_{1} \geq p-c_{1}$ and $u\left(x_{1}\right) \leq p-c_{1}$ for all $x_{1}<p-c_{1}$.

Proof. We prove each statement in turn. For the first claim, suppose not and pick an $x_{1}$ such that $r\left(x_{1}\right)=1$. As $x_{1}$ is accepted with positive probability, the type $\hat{c}\left(x_{1}\right)$ must weakly prefer to accept the offer $x_{1}$. By Lemma $4, x_{2}\left(x_{1}\right) \geq p+\hat{c}(x)$. As $r\left(x_{1}\right)=1$, accepting the offer $x_{1}$ gives type $\hat{c}\left(x_{1}\right)$ at $\operatorname{most} \max \left\{\delta\left(1-x_{2}\right), \delta\left(1-p-\hat{c}\left(x_{1}\right)\right)\right\}=\delta\left(1-p-\hat{c}\left(x_{1}\right)\right)$. But then this type strictly prefers to fight in the first period and this contradiction proves the first claim.

For the second claim, suppose not and pick an $x_{1}$ such that $\hat{c}\left(x_{1}\right)<x_{1}-p$. Then $x_{1}$ will be accepted with positive probability and the type $\hat{c}\left(x_{1}\right)$ must weakly prefer to accept the offer $x_{1}$. For this type, accepting will be agreed to with probability $1-r\left(x_{1}\right)>0$, which 
yields utility $1-x_{1}<1-p-\hat{c}\left(x_{1}\right)$. Otherwise, with probability $r\left(x_{1}\right)$, accepting will be renegotiated which, as in the above, gives this type a payoff of at most $\delta\left(1-p-\hat{c}\left(x_{1}\right)\right)$. Therefore this type strictly prefers to fight in the first period and this contradiction proves the second claim.

For the third claim, simply observe that $x_{2}\left(x_{1}\right) \geq p+\hat{c}(x) \geq p+x_{1}-p=x_{1}$ by the previous part and Lemma 4.

For the fourth claim, if $x_{1}$ is rejected with probability one, then $F\left(\hat{c}\left(x_{1}\right)\right)=1$ and $u\left(x_{1}\right)=p-c_{1}$, as required. So suppose $x_{1}$ is accepted with positive probability. By the first part, $r\left(x_{1}\right)<1$, and so country 1 plays agree with positive probability and, if it is mixing, both agreeing and renegotiating must give equal utility. So $u\left(x_{1}\right)$ is the value to country 1 of agreeing to $x_{1}$, which is the given expression.

For the case of $x_{1}<p-c_{1}$ in the final claim, it is easy to see that the result follows directly from the fourth part of the lemma. So suppose $x_{1} \geq p-c_{1}$. By the second part of the lemma, $\hat{c}\left(x_{1}\right) \geq x_{1}-p$ and so $F\left(\hat{c}\left(x_{1}\right)\right) \geq F\left(x_{1}-p\right)$. Then it follows from the fourth part that

$$
\begin{gathered}
u\left(x_{1}\right)=F\left(\hat{c}\left(x_{1}\right)\right)\left(p-c_{1}\right)+\left(1-F\left(\hat{c}\left(x_{1}\right)\right) x_{1} \leq\right. \\
F\left(x_{1}-p\right)\left(p-c_{1}\right)+\left(1-F\left(x_{1}-p\right)\right) x_{1}=v\left(x_{1}\right) .
\end{gathered}
$$

This proves the final part of the lemma.

The careful reader will note that several parts of the preceding lemmas apply only to offers that are accepted with positive probability. As we shall see, equilibria where this is the case exist and all such equilibria behave as the one-shot ultimatum game as players are sufficiently patient. However, other types of behavior are also possible that involve all types of country 2 rejecting seemingly reasonable offers. Behavior of this form involves all types of player 2 rejecting the first period offer, and player 1 renegotiating with certainty if 2 accepts and player 1 making the second period offer $x_{2}$ based on the belief that player 2 is the very weakest type with probability one. By using this form of construction following certain offers, it is possible to support a large range of offers in equilibrium. While technically legitimate, we find these constructions unappealing for two reasons. First, they require that the weakest type of country 2 fight in the first period, rather than accept, even though this action guarantees her the worst possible payoff. ${ }^{3}$ Thus, these constructions require this type

\footnotetext{
${ }^{3}$ To see this, recall that the weakest type has $c_{2}=1-p$ and thus receives a payoff of zero from war in either period one or period two.
} 
to choose a weakly dominated action. Second, they require country 2 to treat the first period offer as irrelevant as country 2 knows with certainty that this offer will be renegotiated with certainty. If there is some small chance that country 1 will agree, rather than renegotiate, some types of country 2 will prefer to accept rather than fight. This small chance could be justified as the result of trembles on the part of country 1 or by altering the game form to suppose that there is some chance that renegotiation is not possible. More formally, we say that a strong PBE is non-belligerent if every initial offer $x_{1} \in\left[\delta x^{*}, 1\right)$ is accepted with positive probability so that $\hat{c}\left(x_{1}\right)<1-p$.

We are now ready to prove our first main result for the continuous type case. This result shows that there exists a non-belligerent $\mathrm{PBE}$ with the same outcome as the one-shot ultimatum game.

Proposition 5. Suppose the hazard rate $f\left(c_{2}\right) /\left(1-F\left(c_{2}\right)\right)$ is nondecreasing, $f(0)<1 / c_{1}$, and $\delta<1$. Then there exists a non-belligerent $P B E$ with the same equilibrium path as the one-shot ultimatum game.

Before proving this result it is worth noting that unlike the two type case, with a continuum of types for country 2 a second class of non-belligerent equilibria also exist. To see this consider the following example. Suppose the offer $x^{*}$ has been made and let $\delta$ satisfy $x^{*}<\delta<1$. Now define $\bar{c}=\left(x^{*} / \delta\right)-p .^{4}$ It is easy to check that $\bar{c} \in\left(c^{*}, 1-p\right)$. We claim the following is also consistent with equilibrium: after the offer $x^{*}$, the types $c_{2} \geq \bar{c}$ accept the offer, and the types $c_{2}<\bar{c}$ reject the offer. Following acceptance, country 1 mixes between agreeing (with probability $1-r=1-\left(x^{*} / \delta\right)$ ) and renegotiating (with probability $r=x^{*} / \delta$ ). To show that this is true, we first must evaluate the renegotiation part of the tree. If country 1 sees an acceptance, his belief is truncated at $\bar{c}$. As $\bar{c}>c^{*}$, country 1 's offer in the second period will be $x_{2}=p+\bar{c}$.

Now consider the payoff of type $c_{2} \geq \bar{c}$ of country 2 from agreeing. All such types will accept the offer $x_{2}$ in the second period. So the payoff for such a type is

$$
\begin{aligned}
u_{2}\left(A \mid x^{*}\right) & =(1-r)\left(1-x^{*}\right)+(r) \delta\left(1-x_{2}\right) \\
& =\left(1-\left(x^{*} / \delta\right)\right)\left(1-x^{*}\right)+\left(x^{*} / \delta\right) \delta(1-(p+\bar{c})) \\
& =(1-(p+\bar{c}))\left(1-x^{*}\right)+x^{*}(1-(p+\bar{c})) \\
& =1-p-\bar{c} .
\end{aligned}
$$

\footnotetext{
${ }^{4}$ Notice that if $\delta=1$ then the cut point is the ultimatum game cut point.
} 
As this is weakly better than rejecting for all such types, it is sequentially rational for these types to accept. Now consider the payoff of type $c_{2}<\bar{c}$ of country 2 from agreeing. All such types will reject the offer $x_{2}$ in the second period. So the payoff for such a type is

$u_{2}\left(A \mid x^{*}\right)=(1-r)\left(1-x^{*}\right)+(r) \delta\left(1-p-c_{2}\right)=(1-p-\bar{c})\left(1-x^{*}\right)+x^{*}\left(1-p-c_{2}\right)<1-p-c_{2}$.

This shows it is sequentially rational for these types to reject. Finally, we must check that country 1 is indifferent. If it agrees to the acceptance, it receives a payoff of $x^{*}$. If it renegotiates and offers $x_{2}=p+\bar{c}$, under its updated belief it believes this offer will be accepted with probability 1 , so its payoff is $\delta x_{2}$. But we have

$$
\delta x_{2}=\delta(p+\bar{c})=\delta\left(x^{*} / \delta\right)=x^{*}
$$

So country 1 is indifferent, as required.

Clearly, this arrangement exhibits delay. More seriously, note that country 1 receives a strictly lower payoff here than in the standard equilibrium, because more types are rejecting, but it still only gets $x^{*}$ from the smaller set of types that are accepting. It is also true that for any $x$ such that $x^{*} \leq x<\delta$, we can construct a similar sort of mixing situation: country 2 uses a cutpoint given by $\bar{c}=(x / \delta)-p$ and country 1 mixes with probability $r=x / \delta$. So these offers can also exhibit delay. The proof of Proposition 5, which we now give, uses some of these ideas.

Proof. We construct a strong PBE as follows. We begin with the behavior after the desired equilibrium offer $x^{*}$. Let $\sigma$ be a strategy profile such that the initial offer $x_{1}=x^{*}, r\left(x^{*}\right)=0$, $\hat{c}\left(x^{*}\right)=x^{*}-p$, and $x_{2}\left(x^{*}\right)=x^{*}$. Given Lemma 4, it is clear that this behavior forms a mutual best response. For all $x_{1}>x^{*}$, let $\sigma$ be such that $r\left(x_{1}\right)=0, \hat{c}\left(x_{1}\right)=x_{1}-p$, and $x_{2}\left(x_{1}\right)=x_{1}$. Again, given Lemma 4 , it is clear that this behavior is part of a mutual best response. If $\delta<x^{*}$, then for all $x_{1} \in\left[\delta, x^{*}\right)$, let $\sigma$ be such that $r\left(x_{1}\right)=0, \hat{c}\left(x_{1}\right)=x_{1}-p$, and $x_{2}\left(x_{1}\right)=x^{*}$. As the maximum possible payoff to renegotiation is $\delta$, clearly agreeing with probability one is optimal. The choice of $x_{2}$ is optimal by Lemma 4 and so this behavior forms a mutual best response. For all $x_{1} \in\left[\delta x^{*}, \min \left\{\delta, x^{*}\right\}\right)$, let $\sigma$ be such that $r\left(x_{1}\right)=x_{1} / \delta, \hat{c}\left(x_{1}\right)=\left(x_{1} / \delta\right)-p$, and $x_{2}\left(x_{1}\right)=x_{1} / \delta$. Following the reasoning given immediately after Proposition 5 , we can see that this behavior forms a best response. Finally, for all $x_{1}<\delta x^{*}$, let $\sigma$ be such that $r\left(x_{1}\right)=1, \hat{c}\left(x_{1}\right)=1-p$, and $x_{2}\left(x_{1}\right)=1$. Once again, we see that this behavior forms a mutual best response. 
All that remains is to show that offering $x^{*}$ is optimal in the first period. It is easy to see that $u\left(x^{*}\right)=v\left(x^{*}\right)$. As $x^{*}$ is the unique maximizer of $v(x)$, it follows by the last part of Lemma 5 that for all $x_{1} \geq p-c_{1}, u\left(x_{1}\right) \leq v\left(x_{1}\right) \leq v\left(x^{*}\right)=u\left(x^{*}\right)$, so $x^{*}$ is the optimal offer for this range. Moreover, for all $x_{1}<p-c_{1}$, the same part Lemma 5 shows $u\left(x_{1}\right) \leq p-c_{1}<u\left(x^{*}\right)$, so $x^{*}$ is in fact the optimal offer for country 1 . Therefore $\sigma$ is a PBE and is non-belligerent by construction.

Proposition 5 shows that the observed actions of the one-shot ultimatum game can be supported as an equilibrium in our model with retractable offers, though not every nonbelligerent equilibrium has the same outcome as the one-shot version of the model. However, our final result in this section establishes that as $\delta \rightarrow 1$, the outcome of all non-belligerent equilibria converge to the outcome of the one-shot ultimatum game.

Proposition 6. Suppose the hazard rate $f\left(c_{2}\right) /\left(1-F\left(c_{2}\right)\right)$ is nondecreasing and $f(0)<1 / c_{1}$. Then as $\delta \rightarrow 1$, the set of first period offers that can be supported by non-belligerent equilibria converges to the single offer $x^{*}$ and the utility to country 1 of every non-belligerent equilibrium converges to the utility of the one-shot ultimatum game.

Proof. Let $\sigma$ be a non-belligerent equilibrium. We claim that $u\left(x^{*}\right) \geq F\left(\left(x^{*} / \delta\right)-p\right)(p-$ $\left.c_{1}\right)+\left(1-F\left(\left(x^{*} / \delta\right)-p\right)\right) x^{*}$. There are two cases. First, if $r\left(x^{*}\right)=0$, then clearly country 2 uses cutpoint $c^{*}$ and $u\left(x^{*} ; \delta\right)=v\left(x^{*}\right)$ and our claim holds. Alternatively, suppose $r\left(x^{*}\right)>0$. We know from the first part of Lemma 5 that $r\left(x^{*}\right)<1$ in a non-belligerent equilibrium so in fact $r\left(x^{*}\right) \in(0,1)$. By part 2 of Lemma 5 we know that $\hat{c}\left(x^{*}\right) \geq x^{*}-p$ and then it follows from Lemma 4 that $x_{2}\left(x^{*}\right)=p+\hat{c}\left(x^{*}\right)$. Therefore, $x_{2}\left(x^{*}\right)$ will be accepted with probability one and indifference for country 1 requires that $x_{2}\left(x^{*}\right)=x^{*} / \delta$. We conclude that $\hat{c}\left(x^{*}\right)=\left(x^{*} / \delta\right)-p$ and our claim follows from part 4 of Lemma 5 .

A consequence of this claim is that the equilibrium utility of $\sigma$ must be at least $F\left(\left(x^{*} / \delta\right)-\right.$ $p)\left(p-c_{1}\right)+\left(1-F\left(\left(x^{*} / \delta\right)-p\right)\right) x^{*}$, which converges to $v\left(x^{*}\right)$ as $\delta \rightarrow 1$. As $v\left(x^{*}\right)$ is a maximizer of $v(x)$, it follows from the last part of Lemma 5 that the equilibrium utility of $\sigma$ can be no more than $v\left(x^{*}\right)$. This proves the second part of the proposition.

To prove the first part of the proposition, note that by Proposition $5, x^{*}$ is in the set of supportable first period offers for all $\delta$. Now suppose as $\delta \rightarrow 1$ the set of first period offers converges to a set containing other offers as well. Let $x^{0} \neq x^{*}$ be one such offer. Then for $\delta$ values arbitrarily close to 1 , we must be able to find non-belligerent equilibria with first period offers arbitrarily close to $x^{0}$. By the last part of Lemma 5 , we know that $u\left(x^{0}\right) \leq v\left(x^{0}\right)$ in every equilibrium, so by the continuity of $v$, it follows that we must be able 
to find non-belligerent equilibria with equilibrium utility arbitrary close to a value at most $v\left(x^{0}\right)$. But as $x^{*}$ is the unique maximizer of $v, v\left(x^{*}\right)-v\left(x^{0}\right)>0$ and so it is impossible to find non-belligerent equilibria with equilibrium utility arbitrary close to both $v\left(x^{0}\right)$ and $v\left(x^{*}\right)$, as required by the second part of the proposition. This contradiction proves the first part of the proposition.

\subsection{No Commitment to Fighting}

We next turn to the game $G_{R}$, in which acceptance by country 2 ends the game but rejection can be renegotiated. With a continuum of types, this model turns out to be quite complicated and we therefore consider the special case in which $c_{2}$ is drawn uniformly from the interval $[0,1-p]$. We also assume that $c_{1}<1-p$ and let $z=1-\delta(1-p)$. The following Proposition identifies a (strong) PBE to this game. ${ }^{5}$

Proposition 7. For $\delta \geq 2 p /\left(1+p-c_{1}\right)$, the following is the path of play of a (strong) PBE to this game.

Player 1 makes the offer $x_{1}^{*}=\delta\left(\frac{1+p-c_{1}}{2}\right)$ in the first period and makes the offer $x_{2}^{*}=$ $\frac{1+p-c_{1}}{2}-\frac{1-\delta}{\delta}$ in the second period. Player 2 responds in one of three ways, depending on her type. If $c_{2} \in[0, \hat{c}]$, then she rejects both offers and chooses war. If $c_{2} \in\left[\hat{c}, c^{*}\right]$, then she rejects the first offer and accepts the second offer. If $c_{2} \in\left[c^{*}, 1-p\right]$, then she accepts the first offer. On the equilibrium path, $\hat{c}=\frac{1-p-c_{1}}{2}-\frac{1-\delta}{\delta}$ and $c^{*}=1-p-2\left(\frac{1-\delta}{\delta}\right)$.

Proof. We begin with some preliminary points about country 1's initial offer $x_{1}$. If $x_{1}<z$, then all types of country 2 will accept this offer. If $x_{1}>z+\delta \frac{1-p-c_{1}}{2}$, then all types of country 2 will reject this offer and the resulting offer in the second period. This last option is never optimal for country 1.

Now consider an arbitrary offer $x_{1} \in\left[z, z+\delta \frac{1-p-c_{1}}{2}\right]$. We will consider strategies of player 2 such that all types $c_{2}<c^{*}\left(x_{1}\right)$ reject this initial offer and all types $c_{2}>c^{*}\left(x_{1}\right)$ accept this initial offer. Therefore, player 1's belief about the distribution of costs of player 2 in the second period is uniform on the interval $\left[0, c^{*}\left(x_{1}\right)\right]$. As period 2 is just a standard ultimatum game, we can rely on the standard arguments that $x_{2} \in\left[p, p+c^{*}\left(x_{1}\right)\right]$. Indeed, these standard arguments yield $x_{2}=p+\frac{c^{*}\left(x_{1}\right)-c_{1}}{2}$ if $c^{*}\left(x_{1}\right) \geq c_{1}$ and $x_{2}=p$ if $c^{*}\left(x_{1}\right)<c_{1}$. It is easy to see that for sufficiently high $\delta$, country 1 always prefers to continue bargaining into the second period rather than fight.

\footnotetext{
${ }^{5}$ We conjecture that it is the unique such equilibrium.
} 
Now we turn to period 1 . To find $c^{*}\left(x_{1}\right)$ we observe that the offers $x_{1}$ and $x_{2}\left(x_{1}\right)$ must make country 2 indifferent between accepting in period 1 and accepting in period 2 . To see the intuition for why this must be the case, suppose country 2 strictly prefers to accept the offer in the first round. Then all of the types who reject this initial offer will also reject the second offer, leading to war. But then country 1 should adjust the second offer to get a peaceful settlement from these types, and this profitable deviation should not exist in an equilibrium. On the other hand, suppose country 2 strictly prefers the second offer to the first offer. Then all types will wait to the second period to accept the offer. But because of discounting, country 1 should alter its first period offer to induce some types of country 1 to accept in the first period, and this is another profitable deviation. Therefore, all types of country 2 must be indifferent between accepting $x_{1}$ and accepting $x_{2}$.

This indifference implies that $1-x_{1}=\delta\left(1-x_{2}\left(x_{1}\right)\right)$. So if $c^{*}\left(x_{1}\right) \geq c_{1}$, then we have $1-x_{1}=\delta\left(1-p-\frac{c^{*}\left(x_{1}\right)-c_{1}}{2}\right)$. Solving for $c^{*}\left(x_{1}\right)$ gives

$$
c^{*}\left(x_{1}\right)=2\left[1-p-\frac{\left(1-x_{1}\right)}{\delta}+\frac{c_{1}}{2}\right] .
$$

This identifies the cut point between those who reject and accept in the first round. Of the types who reject the first round offer, which reject the second round offer? Let $\hat{c}\left(x_{1}\right)$ be this cut point. Then a type of country 2 with $\operatorname{cost} c_{2}=\hat{c}\left(x_{1}\right)$ is indifferent between accepting and rejecting $x_{2}\left(x_{1}\right)$. But accepting $x_{2}\left(x_{1}\right)$ has the same value as accepting $x_{1}$. So the indifferent type satisfies $\delta\left(1-p-\hat{c}\left(x_{1}\right)\right)=1-x_{1}$. Solving this yields

$$
\hat{c}\left(x_{1}\right)=1-p-\frac{\left(1-x_{1}\right)}{\delta} .
$$

It is possible to show that for all $x_{1} \in\left[z, z+\delta \frac{1-p-c_{1}}{2}\right]$, we have $\hat{c}\left(x_{1}\right)<c^{*}\left(x_{1}\right)$. The interesting thing to note here is that the all types of country 2 with costs $c_{2}>\hat{c}\left(x_{1}\right)$ prefer to settle rather than fight, but some of those types settle in the first period and some choose to do so in the second period.

Now all that remains is to find the optimal offer $x_{1}$. Given the above, the expected utility of this offer is given by

$$
u_{1}\left(x_{1}\right)=\int_{0}^{\hat{c}\left(x_{1}\right)} \delta\left(p-c_{1}\right) \frac{d c}{1-p}+\int_{\hat{c}\left(x_{1}\right)}^{c^{*}\left(x_{1}\right)} \delta x_{2}\left(x_{1}\right) \frac{d c}{1-p}+\int_{c^{*}\left(x_{1}\right)}^{1-p} x_{1} \frac{d c}{1-p} .
$$


Maximizing this expression yields

$$
x_{1}^{*}=\delta \frac{1+p-c_{1}}{2} .
$$

The result follows when $\delta \geq 2 p /\left(1+p-c_{1}\right)$.

Here we again have a similar result to the two type case. Delay occurs in equilibrium, with some types of country 2 waiting until the second period to accept the offer of country 1 . Also, we again have the result that as $\delta \rightarrow 1$, the equilibrium converges to the one-shot ultimatum game.

\subsection{No Commitment to Agreements or Fighting}

Finally we reconsider the game $G_{A R}$ in which there is neither commitment to enact accepted proposals or to fight when an offer is rejected. Here we find that we only have equilibria outcomes that are also outcomes to the game with no commitment to agreements. We also find that as $\delta$ goes to 1 the equilibrium without commitment to fighting or agreements has a distribution over outcomes equal to that of the one-shot ultimatum game.

We first give the following lemma about equilibrium behavior in game $G_{A R}$ that parallels Lemma 2.

Lemma 6. In every equilibrium of the game $G_{A R}$, if the set of types of country 2 that reject an offer $x_{1}$ has positive measure, then country 1 responds to this rejection by fighting with probability one.

Proof. Let $\sigma^{*}$ be an equilibrium of $G_{A R}$ in which after an offer $x_{1}$, the set of types that reject this offer, which we denote $C_{R}\left(x_{1}, \sigma^{*}\right)$, is non-empty. Let $m_{R}$ be the infimum of $C_{R}\left(x_{1}, \sigma^{*}\right)$. As as $C_{R}\left(x_{1}, \sigma^{*}\right)$ is a set of positive measure, it must be that $m_{R}<1-p$. By Bayes' Rule, after observing an rejection, country 1 will place zero probability on the set of types $\left\{c \mid c<m_{R}\right\}$. Therefore, by standard ultimatum game arguments, country 1 will make an offer to country 2 that is no smaller than the war payoff of type $m_{R}$ of country 2 , so that $1-x_{2} \leq p_{2}-m_{R}$. So the maximum payoff achievable by a type in $C_{R}\left(x_{1}, \sigma^{*}\right)$ in the second period is $\delta\left(p_{2}-m_{R}\right)$. Now, moving back to country 1's decision on whether to renegotiate or fight after country 2 's rejection, let $q_{F}$ be the probability that country 1 fights. Then the utility of a type $c_{2} \in C_{R}\left(x_{1}, \sigma^{*}\right)$ of country 2 for rejecting is no more than $q_{F}\left(p_{2}-c_{2}\right)+\left(1-q_{F}\right) \delta\left(p_{2}-m_{R}\right)$. Also, because such a type is choosing to reject instead of 
choosing to fight, this utility is no less than $p_{2}-c_{2}$. So for every $c_{2} \in C_{R}\left(x_{1}, \sigma^{*}\right)$, we have

$$
\begin{gathered}
q_{F}\left(p_{2}-c_{2}\right)+\left(1-q_{F}\right) \delta\left(p_{2}-m_{R}\right) \geq p_{2}-c_{2} \\
\left(1-q_{F}\right) \delta\left(1-p-m_{R}\right) \geq\left(1-q_{F}\right)\left(1-p-c_{2}\right) .
\end{gathered}
$$

To establish the result, suppose that $q_{F}<1$. Because $m_{R}<1-p$, this inequality reduces to

$$
\delta \geq \frac{1-p-c_{2}}{1-p-m_{R}} .
$$

This must hold for every $c_{2} \in C_{R}\left(x_{1}, \sigma^{*}\right)$. But because we can find values of $c_{2}$ in $C_{R}\left(x_{1}, \sigma^{*}\right)$ that are either equal to $m_{R}$ (if $m_{R}$ is a minimum of $C_{R}\left(x_{1}, \sigma^{*}\right)$ ) or arbitrarily close to $m_{R}$ (if not), the right hand side can be made equal to or arbitrarily close to one. This contradiction implies that $q_{F}=1$ and this establishes the result.

Our main result with a continuum of types is that the set of equilibrium outcomes of $G_{A R}$ is a subset of those in $G_{A}$. That is, allowing country one to respond to rejections by country 2 with counter-offers does not add equilibria to the game in which rejection leads to war.

Proposition 8. For all $\delta \leq 1$, every equilibrium outcome of $G_{A R}$ is an equilibrium outcome of $G_{A}$.

Proof. Suppose $\sigma^{*}$ is an equilibrium of $G_{A R}$. We will construct an equilibrium $\sigma^{\prime}$ of $G_{A}$ that has an identical outcome. To begin, consider an arbitrary offer $x_{1}$ by country 1 in the first period and let $C_{A}\left(x_{1}, \sigma^{*}\right)$ be the set of types of country 2 that accept this offer, let $C_{R}\left(x_{1}, \sigma^{*}\right)$ be the set of types that reject this offer, and let $C_{F}\left(x_{1}, \sigma^{*}\right)$ be the set of types that choose to fight in response to this offer.

If $C_{R}\left(x_{1}, \sigma^{*}\right)$ is measure zero, then the construction of $\sigma^{\prime}$ is simple; it is equal to $\sigma^{*}$. As it is optimal for all types to either play accept or fight under $\sigma^{*}$, it is still optimal for these types to take these same actions when the reject option is unavailable. Clearly, the outcome of $G_{A R}$ under $\sigma^{*}$ is identical to the outcome of $G_{A}$ under $\sigma^{\prime}$.

The other possibility is that $C_{R}\left(x_{1}, \sigma^{*}\right)$ has positive measure. In this case, $\sigma^{\prime}$ is equal to $\sigma^{*}$ for all types not in $C_{R}\left(x_{1}, \sigma^{*}\right)$ and $\sigma^{\prime}$ is equal to the fight action in period one for all types in $C_{R}\left(x_{1}, \sigma^{*}\right)$. To see that $\sigma^{\prime}$ represents equilibrium play, we use the Lemma above to note that the equilibrium outcome of every type in $C_{R}\left(x_{1}, \sigma^{*}\right)$ is fighting in period 1 . Therefore these types receive the same utility under $\sigma^{\prime}$ by choosing the fight action instead. 
For those types outside $C_{R}\left(x_{1}, \sigma^{*}\right)$, since a possible deviation to reject gives the same utility as choosing to fight, there is no change in equilibrium incentives for these types when the reject option is removed. Therefore $\sigma^{\prime}$ represents optimal behavior in $G_{A}$. Moreover, the outcome of the types in $C_{R}\left(x_{1}, \sigma^{*}\right)$ is fighting in period 1 and by construction the outcome in $G_{A}$ for these types under $\sigma^{\prime}$ is also fighting in period 1. This shows that the outcome of $G_{A R}$ under $\sigma^{*}$ is identical to the outcome of $G_{A}$ under $\sigma^{\prime}$.

We conclude that for all offers $x_{1}$, the outcome of $G_{A R}$ under $\sigma^{*}$ is identical to the outcome of $G_{A}$ under $\sigma^{\prime}$. Therefore the optimal choice of offer by country 1 must be the same in $\sigma^{*}$ and $\sigma^{\prime}$ and so every equilibrium outcome of $G_{A R}$ is an equilibrium outcome of $G_{A}$.

Unlike the case with two types, we cannot get directly to a unique distribution of outcomes that matches the ultimatum game because $G_{A}$ has multiple equilibria when $\delta<1$, but sufficiently large. As $\delta \rightarrow 1$, however, non-belligerent equilibria follow an equilibrium path of play that is the same as the ultimatum game, and allowing counter-offers after rejection does not increase the set of equilibrium outcomes. Thus the most general model's equilibria have the characteristics of those found in Proposition 6.

\section{Conclusion}

In this paper we have investigated how relaxing the commitment assumptions present in the standard model of crisis bargaining affects equilibrium behavior. Our main finding is that allowing retractable offers does not change the expected equilibrium behavior. The model with retractable offers is observationally equivalent to the one-shot version. Thus, even though there is good reason to believe that agreements need not be binding in crisis bargaining, in equilibrium participants act as though they are.

We have also considered a version of the model in which agreements are final but fighting can be renegotiated. Here we find there can be screening and delay in agreements, as in the standard economic model. However, this is a consequence of the fact that the first side can weaken the bargaining position of the second side by delaying fighting into the second period. Indeed, as $\delta \rightarrow 1$, the equilibrium behavior of the two sides converge to that of the one-shot ultimatum game. Moreover, when we consider a model that incorporates renegotiation of agreements and rejections and gives the responder a chance to resort to immediate war, the equilibrium set is no larger than a model without renegotiation of rejection. In this sense, when it comes to strategic behavior, relaxing the commitment to agreements appears to 
create incentives that dominate the screening incentives of the relaxation of commitments to fight.

In sum, we find that the opportunity to learn from and react to the fact that an offer is agreeable does not change the strategic incentives of a proposer. Thus, even though this opportunity should presumably be present in many crisis bargaining situations, it does not change the expected outcome of these bargains, at least in the context of the ultimatum game. One may wonder if this same result extends to other game forms of crisis bargaining and is thus a truly general finding. It may be that the game-free approach discussed by Fey and Ramsay (2011) may provide insight to this question. We leave this to future research. 


\section{References}

Ausubel, L. M., P. Cramton, and R. J. Deneckere (2002). Chapter 50 bargaining with incomplete information. Volume 3 of Handbook of Game Theory with Economic Applications, pp. 1897 - 1945. Elsevier.

Brito, D. L. and M. D. Intriligator (1985). Conflict, war, and redistribution. The American Political Science Review $79(4)$, pp. 943-957.

Fearon, J. D. (1995). Rationalist explanations for war. International Organization 49(3), 379-414.

Fearon, J. D. (2007). Fighting rather than bargaining. Typescript Stanford University.

Fey, M. and K. W. Ramsay (2011). Uncertainty and incentives in crisis bargaining: Game-free analysis of international conflict. American Journal of Political Science 55(1), 149-169.

Filson, D. and S. Werner (2002, October). A bargaining model of war and peace. American Journal of Political Science 46, 819-838.

Fudenberg, D. and J. Tirole (1991). Perfect bayesian equilibrium and sequential equilibrium. Journal of Economic Theory 53(2), 236 - 260.

Hart, O. D. and J. Tirole (1988). Contract renegotiation and coasian dynamics. The Review of Economic Studies 55(4), pp. 509-540.

Laffont, J.-J. and J. Tirole (1988). The dynamics of incentive contracts. Econometrica 56(5), pp. $1153-1175$.

Leventoğlu, B. and B. L. Slantchev (2007, October). The armed peace: A punctuated equilibrium theory of war. American Journal of Political Science 51(4), 755-771.

Powell, R. (2004, April). Bargaining and learning while fighting. American Journal of Political Science 48(2), 344-361.

Powell, R. (2006, Winter). War as a commitment problem. International Organization 60(1), 169-203.

Schelling, T. C. (1960). The Strategy of Conflict. Cambridge, MA: Harvard University Press. 
Slantchev, B. L. (2003, November). The principle of convergence in wartime negotiation. American Journal of Political Science 97(4), 621-632.

Smith, A. and A. C. Stam (2004, December). Bargaining and the nature of war. Journal of Conflict Resolution 48(6), 783-813.

Tingley, D. H. (2011). The dark side of the future: An experimental test of commitment problems in bargaining. International Studies Quarterly 55(2), 521-544.

Wolford, S., D. Reiter, and C. J. Carrubba (2011). Information, commitment, and war. Journal of Conflict Resolution 55(4), 556-579. 